\title{
Long-Term Contracts in Major League Baseball
}

\author{
Jahn K. Hakes ${ }^{\dagger}$ and Chad Turner ${ }^{\dagger \dagger}$
}

December 2008

\begin{abstract}
Long-term deals are one tool that both players and franchises use to manage risk. That tool has been much discussed and empirically tested with respect to player shirking, and has more briefly, and only theoretically, discussed with respect to reducing variance in future payrolls. Our work looks at how patterns of use of long-term contracts are affected by changes in contracting rules established through collective bargaining and by expected changes in franchise revenue streams. To accomplish this, we have assembled the most complete dataset of MLB player contracts to date. We analyze changes in contract length and dollar value across players of different ability levels, at different points in their careers (contract status), by position, across CBA agreements, and further examine if new stadiums and new television deals impact contract terms. We confirm the earlier finding that player performance is systematically higher during contract years than during the early portion of a long-term contract. We also find that inclusion of contract length information significantly reduces the unexplained variation in player salaries.
\end{abstract}

\section{JEL Classification Codes: L83}

Keywords: Major League Baseball (MLB); long-term contracts; player salaries and performance; collective bargaining agreements (CBA)

'Department of Economics \& Management, Albion College, Albion, MI 49224, E-mail: jhakes@albion.edu, phone: 517-629-0650.

"Department of Finance \& Economics, Nicholls State University, Thibodaux, LA 70310, E-mail: chad.turner@nicholls.edu, phone: 985-448-4194. 


\section{Introduction}

Our topic of interest is the use of long-term labor contracts; we are not the first to use sports data for this purpose. As early as Rottenberg (1956) and eloquently summarized by Kahn (2000), researchers wishing to analyze labor markets have understood the opportunities provided by the widespread availability of productivity and salary measures for professional athletes. While past research has utilized the abundant performance data available, recent advances in performance measures made by sabermetricians, statistically minded members of the Society of American Baseball Researchers (SABR), cast a shadow on the results of past literature that utilized performance measures that have been subsequently shown to be flawed. ${ }^{1}$ Further, due to data availability issues, those studies that involve long-term contracting issues in baseball, which will be outlined below, typically use only a limited sample period or a non-random subset of contracts. Our work seeks to rectify these shortcomings.

The contribution of this paper is to improve the empirical work on contracting in baseball by first utilizing a superior performance measure, but more importantly, by constructing an exhaustive dataset containing the contract status of nearly all players who played between the 1985 and 2007 season seasons, inclusive. ${ }^{2}$ The result of combining this new data with existing salary and performance measures is a complete dataset of performance measure, salary, and contract details for 23 seasons.

Nearly all the modern research on long-term contracting in baseball acknowledges that utilizing long-term contracts involves risk (and mitigating risk) from both the player's perspective and their employer's perspective. Further, researchers acknowledge that differences in contracting outcomes result from changes in the degree of monopsonistic exploitation across a player's career and across time due to changes in the economic conditions facing teams and players. However, due to data limitations, the way researchers often control for these differences is to limit the sample to players who are homogeneous with regard to such characteristic. For example, Krautmann and Oppenheimer (2002) limit their analysis to free agents from 1990 to 1994, and in doing so are comparing players with like bargaining ability operating in like economic environments.

Our more inclusive dataset allows us to explore additional issues. As our dataset spans collective bargaining agreements, we are able to examine to what extent the institutional context under which players and clubs are operating affects the use of long-term contracts. We are able to examine how long-term contracting differs across a number of different measures, including, but not limited to: negotiating constraints (bargaining status), playing ability, age, defensive positions, and market size. Further, with an

\footnotetext{
${ }^{1}$ While the raw statistics that are components in the calculations of performance have been available, it is the translation of these inputs into a single performance measure that has been markedly improved by sabermetricians. See Burger and Walters (2008) for a similar argument.

${ }^{2}$ Our salary data consists of all players on Opening Day rosters, so some marginal players who never made an Opening Day roster may be omitted.
} 
increased sample size and additional degrees of freedom we can re-examine several topics in explored in previous liteature. Among these, we will in this paper (i) note how performance varies across and within contracts, enabling us to add to the literature on shirking, and (ii) examine how deal length affects the standard Scully model of pay and performance, with an eye to evaluating competing theories of the "winner's curse" and risk management strategies. Additionally, unlike much of the previous literature, we analyze both batters and pitchers, and use superior performance measures.

The organization of the remainder of the paper is as follows: Section II briefly reviews the previous literature, paying particular attention to the work done on long-term contracting and the associated incentive effects. Section III briefly describes the creation of our dataset, and provides a number of summary statistics to familiarize the reader with our dataset and our subsequent controls. Section IV provides multivariate empirical results, using OLS regression to provide evidence of shirking in long-term contracts, and utilizing probit and ordered probit analysis to determine the probability a player is signed to a long-term contract. Section V analyzes salary as a function of contract length and other controls in the spirit of Scully (1974). Section VI concludes, and outlines our future plans for research.

\section{Literature Review}

As we will demonstrate empirically in this paper, not all long-term contracts are signed by players that are free agents; however, much of the empirical work on contracting in baseball has either dealt directly with the effect of free agency on both salary and contract length, or the degree to which salary is suppressed before a player becomes a free agent, including the seminal work by Rottenberg (1956). The 1975 Messersmith / McNally decision that loosened the reserve clause, a contractual provision that ensured a player could negotiate with only one team, provided a natural experiment for economists and led to a number of studies on baseball's labor market. ${ }^{3}$ While these works certainly involve pay and performance and implicitly contracts, these works are less directed in the use of contracts per se than they are directed at the issue of monopsonistic exploitation and salary determination. Kahn (1993) was the first to use panel data methods, and found that both arbitration eligibility and free agency led to increased compensation, while only free agency increased the duration of contracts.

A second line of research that more closely resembles our current work are studies that consider the costs of using contracts, and therefore analyze the risk to both contracting parties and incentive effects. The seminal work in this line of research was Lehn (1982), who demonstrated time spent on the disabled list increased coincident with proliferation of long-term contracts. This result is consistent with shirking, but may also be viewed as consistent with management of risk from the employer's perspective. ${ }^{4}$ Krautmann (1990)

\footnotetext{
${ }^{3}$ For baseball, see Sommers and Quinton (1982), Raimando (1983), Scott, Long, and Somppi (1985), and Kahn (1993).

${ }^{4}$ A shortcoming of this work is that the Lehn analyzed only aggregate data and encompassed a relatively short period of time.
} 
suggests that the observed performance declines in the first year could simply be a result of stochastic variation or regression to the mean. ${ }^{5}$ If owners are simply Bayesian updaters, a team will rationally update the mean performance level of a player that has a positive draw, and a reduction in performance levels during the first year of a long-term contract is not necessarily shirking. Scoggins (1993) criticizes Krautmann by noting that the shirking issue is highly sensitive to the performance measure used. ${ }^{6}$ Marburger (2003) compares modern free agents with matched players who played under the reserve clause, and finds evidence that players with long-term contracts do not outperform comparable reserve era players over the same time frame.

There are three papers that warrant special attention in regard to our current undertaking. Krautmann and Oppenheimer (2002) look explicitly at the relationship between player salaries and contract length. The authors suggest players are more risk averse than owners, and thus are willing to tradeoff salary for longer contracts. They allow players' return to performance to vary with contract duration and correct for the simultaneity of contract length and salary by utilizing two-stage least squares, finding that returns to performance decline with contract length. The sample utilized is all potential free agent position players that signed new contracts between 1990 and 1994, while the performance metric utilized is slugging average.

The second is Maxcy, Fort, and Krautmann (2002) who look for ex-ante strategic behavior, defined as increasing performance in the last year before a new contract is signed, and ex-post strategic behavior, defined as reducing performance in the first year after a contract is signed. They compare performance to its three-year moving average in both the single year before or the single year after a new contract is negotiated. Their dataset contains roughly 2700 observations on 353 players, and their preferred performance metrics are slugging average for hitters, and $\mathrm{K} / \mathrm{BB}$ ratio for pitchers. They find that both batters and pitchers spend significantly less time on the disabled list and have significantly above average playing time in the year prior to the contract negotiations, but find that performance is not statistically different in either the year before or year after the new contract. They suggest that incentive mechanisms are

\footnotetext{
${ }^{5}$ Krautmann's argument is straightforward. If production is stochastic, and owners are simply Bayesian updaters of a player's unobservable underlying talent level, a team will rationally update the mean performance level of a player that has had a positive draw from the production distribution. If this positive draw occurs in the season directly before a new contract is signed, we would expect to observe that the level of performance in the following year (where shirking is said to be most likely to observe) to be below the of the previous "contract" year. However, as we will point out below, if this is indeed the case, subsequent seasons in a player's long-term contract should also be expected to below the performance level of the contract year.

${ }^{6}$ While this response is in part related to the fact that the literature had not settled on a performance measure, and of course these researchers did not have the recent sabermetric developments at their disposal, an additional issue in this discussion is that Krautmann used a performance measure that is an "average" statistic (not directly dependent on playing time), while Scoggins used a performance measure that is a "count" statistic (directly dependent on playing time). This distinction is important if one views the propensity to be injured or sitting out as a form of shirking.
} 
sufficient to overcome the propensity to shirk. We perform a similar analysis later in this work.

The third is Maxcy (2004), which is motivated by the empirical result of Maxcy (1997). ${ }^{7}$ Maxcy (2004) criticizes Lehn (1982) and Kahn (1993) for their assumption that the player's willingness to insure motivates long-term contracts. As Maxcy points out, however, marginal players, who would seem especially likely to wish to purchase an "insurance policy" are rarely observed as signing long-term contracts. Therefore, Maxcy presents a theoretical model in which long-term contracts are desirable to the club in order to mitigate both market uncertainty and uncertainty about employee's future productivity. While Maxcy acknowledges the desire for player to insure, in his model, any player with any degree of risk aversion will always prefer a long-term deal to a series of spot contracts.

The main proposition of Maxcy's model is that teams will prefer long-term contracts when the uncertainty in regard to the price of labor services is high relative to the uncertainty in production. He argues that as a player proceeds through his career and obtains additional negotiation power through arbitration and ultimately free-agency, the uncertainty in regard to the price of that player's labor services increases. Therefore, price uncertainty is measured empirically by a series of dummy variables indicating negotiation status, while production uncertainty is measured as the standard deviation of past performance measures. Maxcy then estimates a binary choice probit, where the dependent variable is indicator for long term deal, and corrects for Heckman style selection with a two-step estimation by estimating the probability the player will stay with his current team. The empirical results show that increases in price uncertainty lead to an increased probability of a long-term contract, but only limited support for the production uncertainty measure. ${ }^{8}$

\section{Data}

\section{IIIA. Sources}

As salary data is not reliably available before the 1985 season, we limit our sample to the 1985-2007 seasons, inclusive. Salary data is acquired from Sean Lahman's database,

\footnotetext{
${ }^{7}$ Maxcy (1997) shows that despite the prevailing view of the literature that players are willing to accept a wage that is below the spot wage in exchange for a guaranteed long-term wage, there is no empirical evidence of lower wages associated with long-term contracts. Maxcy (1997) begins with a dataset containing contracts of most players who were under contract between 1986 and 1993, finding 337 long term contracts for position players, 208 for pitchers. While this analysis is similar in spirit to what we undertake here, our dataset is a larger sample, spanning more years, and will use a superior performance metric.

${ }^{8}$ The dataset utilized is the same as reported in the previous footnote concerning Maxcy (1997), and thus is subject to the same criticism. Maxcy also reports that low revenue clubs are more likely to offer long-term contracts to position players, a result counter to one we report in a subsequent section.
} 
version 5.5. ${ }^{9}$ Individual salary information is supplemented by information on opening day team payrolls available from Rodney Fort's website (years prior to 2004), and the USAToday baseball salary database $(2005-2007) .{ }^{10}$ Components necessary to calculate the performance metrics utilized (OPS and OPS against) are collected from Sean Lahman's website, and supplemented with player demographic information available from Retrosheet. ${ }^{11}$ Information on timing of new stadiums is acquired from Hakes and Clapp (2005). Means of the variables above are reported in Table 2.

The primary sources for contracts are Cot's Contracts website (hereafter Cot's), and a MLB transaction database available from Professional Sports Transactions Archive, (hereafter PSTA). ${ }^{12}$ Cot's provides thorough coverage of the latter part of the sample. PSTA provides transactions throughout the period, but transaction coverage varies from season to season, in both depth and detail. We begin with a player's performance history, and attempt to construct the player's contract status in each season in which we observe performance data. If Cot's or PSTA reports a contract, for example, of length three years in 1987, we code the contract as a 3-year deal signed in 1987. Some of subsequent empirical work utilizes contracts as the unit of observation, while other work utilizes the player-season. This transaction would lead to one observation in the former (the contract signed in 1987), and would be related to three observations in the latter (the observation for the player-season in 1987, 1988, and 1989). Absent information about restructuring or extensions, we assume this contract remains in force for the duration of the contract as observed.

Where PSTA and Cot's were silent on contracts, a series of Lexis / Nexis searches was conducted in major US and Canadian newspapers. ${ }^{13}$ Where we can find evidence of a contract being signed in newsprint, we include this information in the dataset. After an exhaustive search, players for whom no information can be found are assumed to have signed one-year contracts. However, we are quite confident that we have located more than $90 \%$ of the long-term contracts. ${ }^{14}$ All told, we are able to locate 929 contracts of

\footnotetext{
${ }^{9}$ The site is http://www.baseball1.com.

${ }^{10}$ These sites are http://www.rodneyfort.com/SportsData/BizFrame.htm and http://content.usatoday.com/sports/baseball/salaries/default.aspx, respectively.

${ }^{11}$ The site is http://www.retrosheet.org.

${ }^{12}$ These sites are http://mlbcontracts.blogspot.com/ and http://www.prosportstransactions.com, respectively.

${ }^{13}$ While our methods evolved as we experimented, the vast majority of our searchers were conducted by searching for the player's name (in quotation marks) within 8 words of the word "contract" in major US and Canadian newspapers. Returned articles were then read for relevant transaction data. Many transactions were located from "Transaction" articles, listing multiple transactions for multiple teams, though information was often found in articles specific to a team's preseason outlook, articles about individual player contract negotiations, season summaries, and others.

${ }^{14}$ Throughout the remainder of the paper, long-term contracts are defined as contracts that are two years of length or longer. While it is impossible to know how many contracts that we have missed, we do also observe the salary history of players, which indicates situations in which it was particularly likely or
} 
two years or more for batters, and 667 contracts of two years or more for pitchers, numbers much larger than any previous study in the existing literature. ${ }^{15}$ A summary of the contracts included in our dataset is provided in Table 1. The table clearly shows that position players (batters) are more likely to receive long-term deals, defined as deals of length greater than or equal to two years, compared to pitchers. The distribution of deal length is highly right-skewed for both batters and pitchers, with the dispersion for batters being wider than that of pitchers.

\section{III.B Cross Tabulations}

In order to get a sense of the types and frequencies of contracts, we present a series of cross-tabulations. Of course, the cross-tabulations provide only a univariate analysis of the conditions affecting the determination of contract length. We subsequently properly control for factors and their interactions by performing multivariate regression analyses, yet we present the cross tabs as they simultaneously motivate our later empirical work and introduce the richness of out dataset. It is important to note that in Tables 3 through 6 below, the unit of observation is a contract, rather than a player-season. Of course, long-term contracts can span CBA regimes, age groups, and even involve position changes. We use the information for the first season for which the contract is in force, as these are the conditions that were relevant at the time of contract negotiation. ${ }^{16}$

Table 3a displays the number of contracts, by deal length and age group for batters, while Table $3 \mathrm{~b}$ displays analogous information for pitchers. What is clear from Table $3 \mathrm{a}$ is that very few of the youngest position players receive long-term contracts; as players gain arbitration and free-agent eligibility, a larger fraction of contracts signed are long-term deals. Even in the 26-29 age group category, as many players are making considerable bargaining gains, just less than $90 \%$ of deals are less than two years in length. ${ }^{17}$

Conditioned on age group, the fraction of deals that are long-term reaches its peak for the 30-33 age group, and this fraction falls as players age. More than $40 \%$ of those contracts of 5 years of length or longer are held by players in the 26-29 age group and nearly $30 \%$ are held by players in the 30-33 age group. Table $3 \mathrm{~b}$ shows similar patterns for pitchers, though two notable differences are the relative scarcity of contracts of five years of length or longer for pitchers and the fact that amongst the oldest age group, pitchers are more

unlikely to find a long-term contract, increasing our confidence that we have found most of the long-term deals. Further increasing our confidence is the fact that cases for which we did have remaining gaps in player's contract history are predominantly found at the beginning of a player's career, for marginal players or both. There remains a small portion of players for whom we have not conducted an exhaustive search of contract history. In future work, we will complete the search process for these players.

${ }^{15}$ As we will see below, unlike previous studies that limit their analysis to free agents, we capture a large number of long-term contracts for players that are unlikely to have achieved free agent status.

${ }^{16}$ For example, consider a player who signed a 4-year contract in the off-season between the 1994 and 1995 and would be 29 years old on opening day of the 1995 season. In our dataset, this player would be coded as belonging to the 1995 - 2001 CBA regime and 26-29 group, as the deal was signed in 1995 and the age at the beginning of the first season of the deal is 29 . 
likely to receive a long-term deal than similarly aged batters. As with the batters, those pitchers with that receive the longest deals are in the 26-29 and 30-33 age group.

Together, the information suggests that players' contract length is constrained by their limited bargaining status early in their careers, and contract length is constrained by the onset of diminished skills associated with aging late in their careers.

Table 4a classifies contracts by deal length and defensive position for batters. The null hypothesis of independence between deal length and defensive positions for batters is rejected at the 5\% significance level. Catchers sign relatively more 2-year contracts more other positional players, but sign fewer contracts of length longer than three years; for shortstops, the pattern is reversed. Of the contracts of three years or more, first basemen and outfielders are overrepresented, while catchers and second baseman are underrepresented. Table $4 \mathrm{~b}$ displays similar information for pitchers, revealing that starting pitchers and closers are much more likely to receive long-term deals than other pitchers. ${ }^{18}$ Another pattern that is revealed is, amongst starting pitchers, left-handed starters negotiate longer contracts. Almost $10 \%$ of left-handed starters have contracts of three years or longer, while for right handed starters, the corresponding figure is just $7 \% .^{19}$

Tables 5a and Table 5b report contracts by deal length and Collective Bargaining Agreement regime (CBA regime), for batters and pitchers, respectively. ${ }^{20} \mathrm{~A}$ striking feature is the paucity of contracts signed under the $1986-1989$ CBA, the so-called collusion era, as fewer than 5 percent of contracts signed for both position player sand hitters between 1986 and 1989 were long-term deals. ${ }^{21}$ Amongst batters, the fraction of players signing long-term deals shows a broad increase after the collusion era, displaying only a slight decline between the 1995 - 01 and 2002 - 06 CBA regimes. For pitchers, the fraction of contracts signed that are long-term has increased and uninterrupted fashion after the collusion era.

\footnotetext{
${ }^{18}$ Starting pitchers are defined as players for whom more than half of their appearances are starts, while relief pitchers (closers) are defined as players for whom more than half of their appearances are games finished.

${ }^{19}$ This pattern appears to be evident for closers. However, one should use caution in drawing inferences as there are very few long-term contracts signed by left-handed closers.

${ }^{20}$ Contracts are coded based on the year (CBA regime) in which the contract was signed. Because our player statistics sample begins in 1985, contracts coded as belonging to the $1981-1985$ CBA are based on those players for whom we observe performance statistics in 1985 and who signed a contract that begins in the 1985 season or began in a season prior to 1985. Thus, our sample contains all players who signed contracts (and played) in 1985, including both one year contracts and long-term contracts signed in 1985. However, also included are players who signed two-year contracts in 1984 (but not one-year contracts signed in 1984), and three-year contracts in 1983 (but not one or two-year contracts in 1983), and so on. This "grandfathering" results in a selection bias - the composition of contracts is the 1981-1985 is selected towards those with longer contracts, which would tend to bias the results of the test of independence between deal length and CBA regime. However, when the test of independence is conducting, omitting the 1981-1985 CBA regime, the p-value is again 0.000.

${ }^{21}$ For additional details on collusion, see Bruggink and Rose (1990).
} 
Tables $6 \mathrm{a}$ and $6 \mathrm{~b}$ offers a preliminary analysis of potential differential use of long-term contracts by teams of different market sizes. In these tables, we examine years remaining on a contract rather than length of the contract, and thus the unit of observation is no longer a contract, but instead a player season. While an examination of contact length by payroll category would enable us to determine if teams with large payrolls sign players to longer contracts (which will later be shown to be correlated with high quality players), the switch to years remaining on contracts also allows the possibility that these large payroll teams acquire players with longer contracts who were originally signed by other teams. This switch allows us to consider the Coasian conjecture that the distribution of talent should be independent of the initial ownership of these resources. The results suggests that low payroll teams have fewer of their position players "locked up" for long periods relative to high payroll teams, a result in contast to that reported by Maxcy (2004). This pattern is also observed for pitchers, with high payroll teams having a larger fraction of players under contract for long periods. The null hypothesis of an independent distribution of years remaining on contract and salary category is soundly rejected at the $1 \%$ significance level.

Table $7 \mathrm{a}$ and $7 \mathrm{~b}$ reports a cross-tab of years remaining on contract by bargaining era, echoing the results of Table $4 \mathrm{a}$ and $4 \mathrm{~b}$. Fewer player-seasons are observed with more than 4 years remaining on the player contract during the 1986-1989 collusion period, and fewer pitchers have many years remaining compared to batters.

Table 8 lends support to the result that better players receive longer contracts, confirming a finding reported by Krautmann and Oppenheimer (2002) and Maxcy (2004), amongst others. Players were assigned to performance quintiles based on their best qualifying season such that 20 percent of player-seasons are assigned to each quintile. Performance quintile 1 (q1) includes those players with the lowest peak performance levels, typically journeyman players, while performance quintile 5 (q5) represents players with the highest peak performance. Players who never reach the qualifying levels in any of their seasons, 130 at bats for hitters and 130 batters faced for pitchers, are not assigned to a quintile. ${ }^{22}$ Table 8 the proportion of player-seasons for which a player is in the last year of their contract declines as higher ability players are examined. Because of the fact that better players get longer contracts, they are less likely than marginal players to be in their "contract year". The pattern is similar fro both batters and pitchers, though the reduction is less dramatic as pitching quality increases, a consequence of the infrequency with which very long-term contracts are observed for pitchers.

\section{Multivariate Analysis of Contracts}

\section{IV.A. Shirking}

\footnotetext{
${ }^{22}$ The number of players in each performance quintile is not equal because players are assigned on the basis of their peak season's performance. The value of peak OPS that would result in exactly $20 \%$ of player-seasons being assigned to each performance quintile is first calculated. In some cases, a player's career spans this value, resulting in a slight deviation from $20 \%$ of player seasons being assigned to each quintile.
} 
In order to properly investigate the possibility of shirking by players who have received longer contracts, it is important to establish an appropriate basis of comparison for players' expected performance over the length of the contract. As has been well established by many researchers, there is a systematic pattern of player development and deterioration that can be observed through a player's career, with a peak at about age 27. More recent research has shown that pattern is more pronounced for hitters of the highest level of peak ability. ${ }^{23}$

The data set contains 6558 instances of consecutive qualifying seasons for hitters, and 5719 such instances for pitchers. An observation of the "first difference" in OPS is possible for each of those instances. The contingent means of those first differences in OPS by age group and ability quintile for the 6558 pairs of hitter player-seasons are displayed in Panel A of Table 9, with the corresponding contingent means for the pitchers first differences in OPS shown in Panel B.

Among players of the highest quality (q5), OPS is increasing by over 0.040 a year for players in their early twenties, and by more than 0.025 a year at ages 24 and 25 before plateauing in the player's later twenties. While players in other quintiles do not improve as rapidly or as much, nearly all players display a steady decline of ability throughout their early-to-mid thirties, with the rate of deterioration increasing for those players still playing in their later thirties. The pattern for pitchers during the early stages of careers is not clear, but their deterioration during their thirties is still apparent. ${ }^{24}$

The expected changes in OPS ( $d o \hat{p} s$ ) for the player's age group and ability level reported in Table 9 serve as the basis of comparison as we attempt to measure under- or overperformance. Subtracting the expected change in OPS from the observed change, the resulting difference-in-differences would be zero if a hitter or pitcher matches expectations, but will take on a negative (positive) value of the hitter (pitcher) underperforms.

$$
\left.d d o p s_{t}=\boldsymbol{Q} p s_{t}-o p s_{t-1}\right\rangle d o \hat{p} s_{t}
$$

To see whether performance drops unexpectedly when a player is not under the pressure of (or, put another way, facing the accountability of) a contract year, we have constructed a series of variables indicators indicating the years left in a player's contract during the season in question. The omitted group ( $y l c 1)$ represents a player in his final year of a contract. As this situation is true of all one-year and contracts, this group contains the

\footnotetext{
${ }^{23}$ See Hakes and Turner (2008).

${ }^{24}$ It is possible that the muddled effects during the early stages of a pitcher's career are due to changes in the pitcher's role on a team. If a player is introduced to MLB by being placed in favorable situations (relief pitching appearances when the pitcher is brought in to exploit platoon/handedness differentials), and in subsequent seasons must adapt to starting pitching against a lineup designed to exploit his own weaknesses, the improvement in the pitcher's OPS allowed would be forced downward, and perhaps even show a deterioration. Fewer position players are used specifically to exploit platoon advantages.
} 
majority of the observations. The remaining three groups, $y l c 2, y l c 3$, and $y l c 4$, indicate that a player has one, two-or-three, and four-or-more guaranteed years left following the current season.

If there is truth to the shirking hypothesis, we would expect to see negative values for ddops for each of the three indicator variables in a simple ANOVA regression. Table 10 shows the results of that analysis, and we see some evidence that this is the case. In Panel A of Table 10, the deviations of player OPS values from expectations increase as the period remaining until the player's next contract increases, and the deviations are statistically significant for players with at least two seasons remaining until their next negotiations. The results for pitchers are less clear. While the point estimates for ddops in Panel B of Table 10 are positive, as we would expect, the magnitudes of the coefficients are not particularly large, and the coefficient is only statistically significant for the group of pitchers with two-or-three years remaining until their next negotiation. Taken as a group, however, the indicators for remaining time on contract are statistically significant for both position players and pitchers, with F-statistics over 6.0 in both cases. $^{25}$

Further exploration of this hypothesis is shown in Table 11, which displays crosstabulations of the ddops statistic by the length of the contract signed, and the remaining years on that contract. Looking first at the results for batters in Panel A, we see that batters in their first year of a two-year contract tend to under-perform in OPS by 0.0265 points, which is more than half of one standard deviation of OPS (about ten standard errors, given the sample size), while relative performance in the contract year $(0.0112)$ does not significantly differ from zero. For position players under 3-year and 4-year contracts, the means show that players systematically underperform until they reach the penultimate year of the contract. ${ }^{26}$ Players under the longest contracts, 5-or-more years, fail to reach expectations until the final three years of their contract, and thereafter match their typical level of play.

Similar patterns are shown for among pitchers in Panel B of Table 11. Pitchers systematically underperform in the first year of a two-year contract, then significantly improve during the second, contract, year. Pitchers with 3-year and 4-year contracts underperform by 0.0198 in OPS until the final two years of the contract, when they return to their expected levels. Pitchers under 5-year or longer contracts also play below

\footnotetext{
${ }^{25}$ Rather than subtracting the expected performance differential (based on age group and performance quintile) from the players actual differential to create the dependent variable above, we also estimated a model where the player's actual performance was the dependent variable and included the player's expected performance differential as an independent variable (along with the categorical variables above). The coefficient on expected performance was not statistically different from 1, and the coefficients on the categorical variables were nearly identical.

${ }^{26}$ Interestingly, players under 3-year and 4-year contracts actually play somewhat above expectations during the season just before their contract year. In subsequent analysis, we will see if there is evidence of a significant number of contract extensions being signed by players at this stage of a long-term contract.
} 
expectations early on in their contracts, and recover in the final seasons. These patterns are consistent with the shirking hypothesis.

\section{B. Contracts by Performance Quintile}

Given that players under long-term contracts are subject to a lower level of accountability from their employers, teams will attempt to limit the issue of those contracts and allow them only to the players with the greatest negotiating positions, especially the top-quality players on the team. To demonstrate the extent of this selection effect, Table 12a reports the number of contracts of each length by player ability quintile, and Table $12 \mathrm{~b}$ repeats the process for quintiles of pitchers. As one would expect, the distribution of contracts skews towards longer deals as ability increases, so that position players in the top quintile of ability (q5) are more than four times as likely to obtain a multi-year contract (twoyears or more) as a marginal player in quintile 1, and the elite players are more than ten times likelier to get a contract of five years or longer. The pattern for pitchers is not as pronounced as for position players. Teams are very stingy with five-year or longer contracts with pitchers, awarding them in less than one percent of signed deals even with the most elite pitchers. The pattern is contained mostly to 2-to-4 year deals, with the best pitchers signing multi-year deals at a rate about 5.7 times more often than marginal pitchers. Even here, however, the likelihood of a multi-year deal increases with player ability slower than with position players, and there appears to be a discrete jump in multiyear contract likelihood between the bottom two quintiles.

Long-term contracts in MLB came into existence along with free agency more than three decades ago. The free agency period has witnessed a great deal of labor strife, as the relative shift of negotiating power towards players was challenged by owners. In addition to repeated brinkmanship during negotiations of each collective bargaining agreement (CBA) since before free agency began, Commissioner Peter Ueberroth organized team owners to restrain themselves from competing for player contracts during the 1986 and 1987 seasons. $^{27}$ Evidence of owner collusion can be seen in Table 13, which displays the proportions of position players and pitchers playing under long term contracts by ability quintile and CBA era. While the proportions for the 1981-85 era are likely overstated due to selection effects among contracts signed prior to 1985 , it is clear that multi-year contracts were much less common for players of all ability levels during the 1986-1989 period compared to any other time period within our sample.

\section{C. Probit Regression Models}

The cross-tabulation results previously shown are helpful in establishing partial correlations between multi-year contracts and these factors, but they do not allow for determining the relative importance of these correlates. We have used probit and ordered

\footnotetext{
${ }^{27}$ Owner collusion has been alleged on many other occassions as well, either with respect to the free agent market in general, or with respect to individual players (such as defectors to the Mexican League during the 1950s, or with Barry Bonds during the 2008 season). For this paper, we limit ourselves to commenting on Collusions I and II, which were litigated formally, and had legal damages awarded by the court system against players demonstrated to have been harmed by the collusion.
} 
probit regressions to determine which of these factors have a statistically significant effect upon predicting a multi-year contract after controlling for all other factors.

While we have recorded many " $1+1$ " contracts, with one guaranteed year followed by a (usually, team) option for a second season, the aspect of the contracts we are trying to capture here is a team's willingness to make a commitment to a contract that extends well into the future. For the purposes of the following analysis, therefore, we define a multiyear contract as a contract of two or more years.

The likely predictors of a player signing a multi-year contact that we have discussed earlier are the player's age, productivity, defensive position, and the negotiating context established under the active collective bargaining agreement.

The youngest players, who are within the first six years of their Major League service, are still constrained to negotiate with their current team. This lack of freedom to contract will reduce their potential to secure a long-term agreement. The oldest players are at a point in their careers where a decline in productivity is expected, and teams will be reluctant to risk a long-term commitment with them. Using the group of players near their production peak, at ages 26-29, as a basis of comparison, we therefore expect younger players to be much less likely to obtain multiyear contracts. Players slightly older than the reference group should have a higher probability of a multiyear contract due to the onset of free agency, but the likelihood of multiyear contracts should thereafter fall with age.

The probit results in Table 14 show that this is indeed the case. In Model 1 of Table 14, where the probit coefficients have been converted into marginal effects, players in the 23 and-under and 24-25 year-old age groups are both 7.1 to 7.7 percent less likely to obtain a multi-year contract. In Model 3, which is constrained to contracts for pitchers, the point estimates are slightly lower but still statistically significant, indicating multi-year deals are 4.9 to 5.4 percent less likely for young pitchers. Models 2 and Model 4 of Table 14 demonstrate that this is due to negotiating constraints, as limiting the sample to free agents removes these negative effects.

Compared to position players, advanced age has a somewhat less pronounced effect upon pitchers' prospects for multi-year contracts. Model 2 also shows that, compared with 2629 year-olds, 34-37 year-old position players are about 3.8 percent less likely to sign a multi-year contract, other things equal, while players age 38 or older are about 18 percent less likely to obtain a multi-year deal. The corresponding coefficients for pitchers' contracts reveals that the probability of a long contract, compared to the rate for 26-29 year-olds, is not significantly lower for 34-37 year-old pitchers, and about 11.3 percent lower for pitchers age 38 or older.

Player quality affects the likelihood of a long-term contract in the expected manner. Among contracts signed by six-year or more veterans in Model 2, we see that the gap between ability quintiles ranges between 5.7 and 11.5 percentage points, so that a member of the elite group of players is 19.8 percent more likely to sign a multi-year deal 
than a player in the median quintile, and players of median ability are 14.0 percent more likely to get a multi-year deal than a marginal player. The pattern is slightly different for pitchers, where the largest distinction is between the bottom quintile of pitchers and the rest, while the multi-year deal probabilities for the top four quintiles are separated by less than 11 percentage points.

The omitted categorical variable for defensive position is first base. Although Models 1 and 2 of Table 14 show insignificant differences between most positions, in both models it is clear that shortstops are the most likely recipients of a multi-year contract, other things equal, and are likely to sign longer deals by about 7.1 to 9.0 percentage points. Among pitchers, lefties are more likely to be recipients of a multi-year deal than righties, other things equal. In general, starting pitchers and closers are 22 percent and 21 percent more likely to obtain multi-year contracts, respectively, than middle relievers. After taking role and other variables into account, however, the probabilities for multi-year deals for lefties are higher by 27, 10, and 12 percent for closers, middle relievers, and starters, respectively.

Our set of categorical variables for collective bargaining regimes clearly shows the effects of owner collusion on contracts during the CBA in effect during the 1986 to 1989 signing period, while Peter Ueberroth was commissioner. Signing rates of multi-year contracts for all position players were at least 6.1 percentage points below the rates in any other CBA regime, and at least 9.2 percentage points below any other regime among contracts for veteran position players. While the number of contracts signed under the newest CBA, which affects only 2007 signings, is still low, the results show far indicate that multi-year deals are being signed at an unprecedented rate. ${ }^{28}$

\section{D. Ordered Probit Regressions}

While the results of the preceding probit models help demonstrate which factors most strongly correlate with the likelihood of a multi-year contract, the use of a dichotomous indicator obscures some of the information that would otherwise be revealed by the length of those multi-year contracts. There is a great deal of difference between a twoyear and a six-year contract, and to pool all multi-year deals into one category leads to concern over the possibility of biased estimators. To verify the robustness of our results, Table 15 replicates the analysis in Table 14 using the ordered probit regression technique.

In this instance, the dependent variable $d l c$ contains an ordered series of five categories, where category 1 is a one year contact, 2 is a one-plus-one contract (that is, one guaranteed year plus a one-year option that is usually at the team's discretion), 3 is a twoyear contract, 4 is a three-year or four-year contract, and 5 is a contract for five or more years. The latter categories pooled multiple contract lengths because the scarcity of contracts this long threatened to leave us with too few degrees of freedom to identify the coefficients otherwise.

\footnotetext{
${ }^{28}$ Information on contracts signed before 1986 are omitted, as the contracts we have are subject to selection bias. See footnote 20 .
} 
As the results in Table 15 show, the ordered probit models mostly echo the results of the original probit model. The coefficients shown are probit coefficients, which represent the change in the fitted Z-score for the latent variable. The age group patterns are replicated, as are the effects of ability quintile and the CBA regime. There are still no positive and significant effects from the debut of a new ballpark. Among defensive positions, shortstops are still more likely to obtain a long-term contract, and in these models we see that catchers also have positive coefficients in both Model 1 and Model 2, although the effects are not statistically significant, with p-values just above the $10 \%$ significance level.

One additional bit of information is given by the relative magnitude of the cut-points. Even the first cut point is at 1.6 standard errors in Model 2 or Table 15, while the gaps between the first and the two following cut points are relatively smaller. This reveals that once a player has the characteristics deemed worthy of a multi-year deal, there is very little empirical evidence to distinguish between a one-plus-one contract and a two-year guaranteed contract, or even a 3-4 year deal. By contrast, the gap between the cut points predicting between 3-4 year deals and a 5+ year deal is relatively quite large, at about 0.8 standard deviations for position players, and an even larger 1.2 standard deviations for pitchers. The exclusion of 5-plus-year deals to a very select minority of players, and even fewer pitchers, is evidence of a possible allowance for greater forecasting error of pitcher productivity due to injury risk or potential loss of effectiveness.

\section{V.A. Salary Regressions}

The patterns displayed in Tables 14 and 15 are consistent with our expectations of how the likelihood of multi-year contracts would change with respect to age, ability, defensive position, and bargaining context. The market equilibrium in contract negotiations for long-terms deals, however, must consider both deal length and salary considerations. To obtain a complete picture of how multi-year deals affect the MLB labor market, we must also look at the effects of these deals upon player salaries.

As discussed previously, one might hypothesize any of several patterns distinctive to multi-year deals. From the player's perspective, the advantage of a longer contract is that the guaranteed pay is a type of insurance against injury or declining ability that he is buying from his employers. Normally, insurance of that type is associated with a risk premium, which would show up in salary levels, other things equal, as a decrease in salary in return for a longer contract. As we will show in the upcoming results in Table 16 , however, longer contracts are associated with higher salaries rather than lower ones, so this hypothesis is rejected by the data, a finding similar to Kahn (1993).

Teams, of course, are free to choose which players to whom they may offer longer contracts. As maximizing agents, we would expect teams to prefer to offer multi-year deals to players who would be difficult to replace in the annual labor market, those with exceptional productivity, and particularly those at defensive positions requiring extraordinary dexterity and skill (as we saw with the shortstop indicator in Tables 14 and 
15). As a result of this selection, which might also include considerations of the individual player's likelihood of shirking, the team might decide that the player's valuable services for a prolonged period are worth the risk of potential injury, decline, or shirking. It would become unclear, however, whether the net benefit after these calculations would predict a salary premium to the player or a discount. This would become an empirical issue. In this extreme tail of the distribution, there is the additional question of whether the returns to ability among these elite players are linear, or even loglinear.

One final hypothesis regarding salary returns to long-deals comes from game theory. That hypothesis is that the frenzied rhythms of bids, offers, and counter-offers - often among several teams - for a unique player's services can result in systematic overbidding for the contracts of the elite players. This "winner's curse" is one possible mechanism that would lead to the non-linear returns to ability discussed in the previous paragraph. ${ }^{29}$ In a scenario where the winner's curse results in very large, very long contracts to the best players, we would expect that this correlation would result in large positive coefficients on indicators of long contracts, with the coefficients increasing exponentially in contract length.

To examine the effects of multi-year deals upon player salaries, Table 16 shows the estimates for four models, one pair pertaining to position players and the other pair to pitchers. Models 1 and 3 are designed along the lines of the second stage of a Scully regression, and predict logged salary (that is, $\ln$ (salary) ) as a function of player ability, defensive position, age, freedom to negotiate, and the player's context in terms of whether he is on a high- or low-payroll team or on a team either playing in or about to move into a new ballpark. A set of indicator variables for each season is included to control for salary inflation over the years, and other market-wide effects such as the 1994-95 player strike, the collusion era of 1986-87, changes in media contracts, etc.

The coefficients in Models 1 and 3 of Table 16 match the results found by other researchers, and establish the basis of comparison for our multi-year contracts addition. Increased ability to negotiate contracts through arbitration eligibility or free agency increases log-salaries substantially, with expected salary increases of 116 percent and 442 percent over the salaries of otherwise similar players still under the reserve clause. ${ }^{30}$

The returns to current productivity for position players are such that a one standard deviation increase in OPS (about 0.155) leads to an expected 20 percent increase in salary. The OPS quintiles control for the player's quality cohort, so as to pick up non$(\log )$ linear effects in the labor market, and show that there are increasing salary premiums paid to higher ability cohorts. The positional indicators show salary premiums to middle infielders and designated hitters, and lower salaries for catchers and third basemen, relative to outfielders. The well-documented pattern of rising salaries for younger

\footnotetext{
${ }^{29}$ See Burger and Walters (2003).

${ }^{30}$ These and subsequent percentage point expected salary increases are obtained with the formula $100 *(\exp (\beta)-1)$.
} 
players and falling salaries for older players is evident, and the control variables for large- and small-payroll teams have the expected signs. One minor surprise is that salaries appear to be slightly depressed (about 17 percent lower) in the two years prior to the debut of an employer's new ballpark.

The coefficients determining pitcher's salaries in the basis-of-comparison Model 3 of Table 16 are quite similar. The expected returns to arbitration eligibility and free agency are somewhat smaller than for position players (about 99 percent and 320 percent, respectively), but are much less sensitive to OPS allowed. A one standard deviation decrease in OPS allowed to opposing hitters only results in an expected 3.6 percent salary increase. Similarly, the relative standing effects of the ability quintiles are much smaller. While the effects of being on a high- or low-payroll team are similar to those for position players, there are no significant effects of playing on a team either in a new ballpark, or about to move into a new park. The positional differences between pitchers' roles is a significant determinant of salary, however, with starters (either right- or left-handed) typically earning 120 percent more than middle relief pitchers, right-handed closers earning on average about 70 percent more than middle relievers, and lefty closers being paid about 92 percent more than middle relievers. The adjusted R-squared measure for goodness of fit for the model is about 0.67 for position players and about 0.70 for pitchers, which is about average for a model of this type.

Models 2 and 4 of Table 16 introduce sets of indicator variables to add information on contract structure. The variable $d l c$ is short for deal-length category, and is divided into five levels. The first level is for one-year deals, and the second level is for one-plus-one contracts. The subsequent levels $(3,4$, and 5) represent two-year deals, three-and fouryear deals, and five-or-more-year contracts, respectively. To capture the possibility that contracts signed one-or-more years before the current season might be systematically larger or smaller than recently-signed contracts, a group of indicators called yrsincat is included. The omitted level of yrsincat is for contracts in their first year, which will include all one-year contracts and freshly-signed multi-year deals. The other categories of yrsincat are for the second year of a contract, for the third and fourth years, and for being in the fifth or later year of a contract.

Given the obvious relationship between the sets of indicators, the interpretation is subtle. For example, consider a two-year guaranteed contract using the coefficients reported in Model 2 of Table 16. Compared to the salaries under a pair of one-year deals with other considerations equal (that is, the player remains in the same age group, and the contract does not affect his performance), the player will receive a premium of about 66 percent (coef. $=0.509$ ) on his salary during the first year of the deal. During the second year, however, the effect will be a salary will still be positive, this time about 19 percent higher than he might have otherwise expected (coef. $=0.509-0.338=0.171)$. For all multi-year deals here, the pattern is a high premium in the first year of a contract, with the premium declining (but not disappearing) through the subsequent years.

Returns to pitchers of long-term contracts follow a somewhat similar pattern in most instances. For a hypothetical two-year contract to a pitcher, the first year offers a 
premium of 85 percent $($ coef. $=0.617$ ), while the second year premium is a still significant 54 percent (coef. $=0.617-0.183=0.434$ ). The largest difference is for the longest contracts, those extending at least 5 seasons. The coefficient for the longest yrsincat indicator (-1.367) is larger than the magnitude of the deal length coefficient (1.214), meaning that in the final year(s) of a five-plus year long pitcher's contract, the pitcher is earning less than he would have with similar production under shorter deals. That is, the pitcher is taking a salary decrease of approximately 14 percent in order to obtain the longer deal. The reluctance of teams to sign long deals with even the most elite pitchers without commanding this salary concession reflects the additional risk pitchers pose of injury or ability decline over time. So even though the hypothesis is rejected that productivity risk premiums dominate the salary differentials in longer contracts, there is evidence that risk is being considered, although perhaps not as the primary factor.

\section{B. Two-stage Least Squares (2SLS) Regressions}

As Krautmann and Oppenheimer (2002) noted, to correctly estimate a system involving simultaneity between endogenous variables, it is necessary to identify the structure of the system of equations and one or more instrumental variables so that the system is identified. In this instance the two "goods" being allocated are contract length and dollar value per season (expressed as $\ln ($ salary)), with the player's utility increasing in both goods and the team's value function decreasing as dispersement of those goods increases.

We will construct the system so that the player objective is to increase contract length as a function of salary and his risk of a performance decline. Although that risk of performance decline certainly contains an unobservable component known privately to the player, we can proxy for some of this risk through variables that are actuarially correlated to performance declines, specifically aging and defensive position.

$$
\text { deallength }_{i}=f\left(\ln \left(\text { salary }_{i} \text {, age } \text { group }_{i}, \operatorname{position}_{i}\right)\right.
$$

The second equation in the system is constructed from the team's perspective as they consider the player's expected marginal revenue product, which will depend upon both expected production and expected market conditions as they attempt to sell tickets and concessions, lease luxury boxes and obtain other revenue streams from media rights, naming rights, merchandising, and so on. More specifically, their willingness to pay for a particular player each season will be a function of the contract length, player ability and current production, defensive prowess (proxied by defensive position or pitching role), the player's ability to freely negotiate salary, the team's market size (here measured by payroll level rather than population, although this is subject to change in later drafts), and the potential extra revenue that might be generated through performing at a new stadium, or willingness-to-pay players to promote fan interest in a stadium about to open.

$$
\begin{gathered}
\ln \left(\text { salary }_{\mathrm{i}}=\mathrm{f}\left(\text { deal length }_{\mathrm{i}}, \mathrm{OPS}_{\mathrm{i}}, \text { ability }_{\text {group }}, \text { position }_{\mathrm{i}},\right. \text { free agent/arbit, new }\right. \\
\text { stadium open/soon, high/ low team payroll }
\end{gathered}
$$


There are several exogenous variables in equation (3) that identify salary in equation (2), and the age group variables in equation (2) identify deal length in equation (3). In future drafts, we hope to have information on player injury histories, which might be a better instrument for risk of production declines, and this would allow us to include age group in equation (3) as a predictor of MRP.

When the model is estimated, the results largely follow those of the OLS results above. The returns to OPS_against for pitchers are realized with more error than returns to OPS for batters, which may be due to systematic bias in the OPS measure based upon the situations in which a pitcher is used (such as left-handed pitchers brought in for one batter to exploit platoon advantages against left-handed batters). Among the positional estimates, the 2SLS model indicates that second basemen and designated hitters receive shorter but more lucrative contracts, other things equal, than the baseline group of outfielders. Catchers, however, tend to receive slightly longer contracts, albeit for smaller dollar values, perhaps reflecting the insurance value to the team of having a reserve catcher (the defensive position with the rarest skill set) available, even if he is not on the field generating production statistics.

\section{Conclusion}

Much work remains to be done. In addition to confirming the terms of the remaining missing contracts, we seek to collect information on player injuries (both disabled list (DL) stints and off-season/late season injuries and surgeries that do not result in a trip to the DL) and on more precise signing dates, so that we might explore how teams manage their rosters and compete for talent within the annual baseball player job market. More important for the quality of our research here, we wish to obtain player injury data to improve the instrumention in the two-stage least squares regression model.

With those caveats in mind, we have made some progress. Through use of a large data set of Major League Baseball player contracts from 1985 to 2007, we have addressed several topics of interest to economists. We add confirming evidence to earlier models of the effects of monopsony and bargaining constraints upon labor markets, and are able to find empirical support for the hypothesis that player performance systematically varies during longer contracts in a manner suggestive of shirking. Probit and ordered probit models show that position players are more likely to obtain long-term contracts than pitchers and that higher-ability players obtain longer deals. Both of these findings are consistent with models of risk management. Finally, (subject to confirmation with a model correcting for simultaneity) we show that inclusion of information regarding a player's contract status -referring to both the length of the contract and its remaining duration - significantly increases the explanatory power of log-salaries in pay-and-performance models, and shows that while pitchers must pay an implicit risk premium for a contract extending five years or more, the best position players are rewarded with contracts that are both more lucrative and longer. 


\section{References}

Bruggink, Thomas H. and Rose, David R. Jr., "Financial Restraint in the Free Agent Labor Market for Major League Baseball: Players Look at Strike Three", Southern Economic Journal, 56, 1029-1043.

Burger John and Walters, Stephen. 2003. "Market Size, Pay and Performance A General Model and Application to Major League Baseball," Journal of Sports Economics, 4, 108-125.

Hakes, Jahn K and Clapp, Christopher M. 2005. "How Long a Honeymoon? The Effect of New Stadiums on Attendance in Major League Baseball, Journal of Sports Economics, 6, 237-263.

Hakes, Jahn K and Turner, Chad S. 2008. "Pay, Productivity and Aging in Major League Baseball", unpublished manuscript.

Kahn, Lawrence M. 1993. "Free Agency, Long-Term Contracts and Compensation in Major League Baseball: Estimates from Panel Data," The Review of Economics and Statistics, 75, 157-164.

Kahn, Lawrence M. 2000. "The sports business as a labor market laboratory", Journal of Economic Perspectives, 14, 75-94.

Krautmann, Anthony C. and Oppenheimer, Margaret. 2002. "Contract Length and the Return to Performance in Major League Baseball”, Journal of Sports Economics, 3, 6-17.

Krautmann, Anthony C. 1990. "Shirking of Stochastic Productivity in Major League Baseball”, Southern Economic Journal, 56, 961-968.

Lehn, Kenneth. 1982. "Property Rights, Risk Sharing, and Player Disability in Major League Baseball", Journal of Law and Economics, 25, 341-366.

Marburger, Daniel R. 2003. "Does the Assignment of Property Rights Encourage or Discourage Shirking? Evidence From Major League Baseball”, Journal of Sports Economics, 4, 19-34.

Maxcy, Joel G. 1997. "Do Long-Term Contracts Influence Performance in Major League Baseball?" In Hendricks, W. (Ed.) Advances in the Economics of Sport. Volume 2, pp. 157-176. Greenwich CT: JAI Press Inc.

Maxcy, Joel G. 2004. "Motivating Long-Term Employment Contracts: Risk Management in Major League Baseball." Managerial and Decision Economics, 25109-120. 
Maxcy, Joel G., Fort, Rodney D., and Krautmann, Anthony C. 2002. "The Effectiveness of Incentive Mechanisms in Major League Baseball", Journal of Sports Economics, 3, 246-255.

Raimondo, Henry J. 1983. "Free Agents' Impact on the Labor Market for Baseball Players", Journal of Labor Research, 4, 183-193.

Rottenburg, Simon. 1956. “The Baseball Players' Labor Market”, Journal of Political Economy, 64, 242-258.

Scott, Frank A. Jr., Long, James E., and Somppi, Kevin. 1985. "Salary Vs. revenue product under monopsony and competition: the case professional basketball," Atlantic Economic Journal, 13, 50-59.

Scoggins, John F. 1993. Shirking or stochastic productivity in Major League Baseball: Comment. Southern Economic Journal, 60, 239-240.

Scully, Gerald W. 1974. "Pay and Performance in Major League Baseball”, American Economic Review, 64, 915-930.

Sommers, Paul M., and Quinton, Noel. 1982. "Pay and Performance in Major League Baseball: The Case of the First Family of Free Agents", Journal of Human Resources, 17, 426-436.

Zimbalist, Andrew. 1992. "Salaries and Performance: Beyond the Scully Model," In Diamonds are Forever, P. Sommers ed., Brookings, 1992: Washington D.C. 
Table 1: Deal length

\begin{tabular}{|l|l|l|}
\hline Deal Length & Batters & Pitchers \\
\hline 1 & 6,965 & 6,316 \\
\hline $1+1$ & 98 & 81 \\
\hline 2 & 397 & 327 \\
\hline 3 & 262 & 207 \\
\hline 4 & 146 & 101 \\
\hline 5 & 88 & 24 \\
\hline 6 & 20 & 5 \\
\hline 7 & 8 & 2 \\
\hline 8 & 3 & 1 \\
\hline 9 & 2 & -- \\
\hline 10 & 3 & -- \\
\hline Total & 7,992 & 7,064 \\
\hline
\end{tabular}

Note: Row labeled $1+1$ refers to players with one year contract with a one-year option. 
Table 2a: Summary statistics by deal status, batters

\begin{tabular}{|c|c|c|c|c|c|c|c|}
\hline variable & mid deal & 1 & $1+1$ & 2 & $3-4$ & $5+$ & All \\
\hline age & 31.35 & 27.84 & 32.76 & 31.57 & 29.15 & 28.71 & 28.79 \\
\hline age23u & 0.006 & 0.113 & 0.000 & 0.003 & 0.054 & 0.056 & 0.083 \\
\hline age 2425 & 0.032 & 0.197 & 0.010 & 0.020 & 0.076 & 0.137 & 0.150 \\
\hline age2629 & 0.245 & 0.406 & 0.184 & 0.254 & 0.414 & 0.419 & 0.366 \\
\hline age3033 & 0.471 & 0.180 & 0.367 & 0.438 & 0.365 & 0.298 & 0.259 \\
\hline age3437 & 0.211 & 0.079 & 0.357 & 0.259 & 0.086 & 0.089 & 0.115 \\
\hline age38up & 0.035 & 0.025 & 0.082 & 0.025 & 0.005 & 0.000 & 0.027 \\
\hline debutyear & 1988.5 & 1990.7 & 1990.4 & 1988.4 & 1989.3 & 1988.4 & 1990.5 \\
\hline dealyr & 1996.0 & 1995.7 & 2000.6 & 1997.2 & 1996.2 & 1995.0 & 1995.8 \\
\hline deallength & 3.424 & 1.000 & 1.000 & 2.000 & 3.358 & 5.548 & 1.241 \\
\hline yrsin & 2.890 & 1.000 & 1.000 & 1.050 & 1.167 & 1.766 & 1.023 \\
\hline yrsleft & 0.9276 & 0.0000 & 0.0000 & 0.9496 & 2.1912 & 3.7823 & 0.2177 \\
\hline obp & 0.346 & 0.314 & 0.332 & 0.329 & 0.345 & 0.358 & 0.323 \\
\hline $\operatorname{slg}$ & 0.437 & 0.376 & 0.417 & 0.393 & 0.434 & 0.478 & 0.392 \\
\hline ops & 0.783 & 0.689 & 0.749 & 0.722 & 0.779 & 0.836 & 0.715 \\
\hline $\mathrm{rc} 27$ & 4.177 & 3.312 & 3.818 & 3.558 & 4.098 & 4.707 & 3.547 \\
\hline $\mathrm{rc}$ & 68.35 & 37.43 & 49.45 & 49.12 & 72.98 & 89.43 & 46.22 \\
\hline $\exp$ & 9.384 & 4.952 & 10.102 & 8.801 & 7.002 & 7.387 & 6.144 \\
\hline salary & 4485235 & 640530 & 2035029 & 1710394 & 2903889 & 4563755 & 1596100 \\
\hline isal & 2.573 & 0.531 & 1.018 & 1.182 & 2.047 & 3.054 & 1.058 \\
\hline Insal & 14.93 & 12.76 & 14.11 & 14.00 & 14.50 & 14.77 & 13.34 \\
\hline Inisal & 0.723 & -1.209 & -0.328 & -0.112 & 0.456 & 0.803 & -0.682 \\
\hline teamsalhi & 0.304 & 0.183 & 0.204 & 0.196 & 0.250 & 0.315 & 0.212 \\
\hline teamsallo & 0.108 & 0.250 & 0.184 & 0.179 & 0.162 & 0.089 & 0.213 \\
\hline q1 & 0.0690 & 0.2561 & 0.0612 & 0.1505 & 0.0792 & 0.0732 & 0.2353 \\
\hline $\mathrm{q} 2$ & 0.1181 & 0.2292 & 0.2245 & 0.2041 & 0.1460 & 0.0976 & 0.2211 \\
\hline q3 & 0.1662 & 0.2090 & 0.2245 & 0.2423 & 0.1955 & 0.1057 & 0.2085 \\
\hline $\mathrm{q} 4$ & 0.2607 & 0.1747 & 0.2245 & 0.2398 & 0.2723 & 0.2358 & 0.1851 \\
\hline q5 & 0.3860 & 0.1311 & 0.2653 & 0.1633 & 0.3069 & 0.4878 & 0.1499 \\
\hline dlc & 4.0321 & 1.0000 & 2.0000 & 3.0000 & 4.0000 & 5.0000 & 1.3268 \\
\hline dops & -0.0080 & -0.0039 & 0.0023 & -0.0369 & -0.0187 & -0.0279 & -0.0079 \\
\hline ddops & 0.0009 & -0.0002 & 0.0164 & -0.0267 & -0.0153 & -0.0261 & -0.0024 \\
\hline ylc1 & 0.4719 & 1.0000 & 1.0000 & 0.0320 & 0.0262 & 0.0420 & 0.7318 \\
\hline ylc2 & 0.2705 & 0.0000 & 0.0000 & 0.9680 & 0.0367 & 0.0672 & 0.1276 \\
\hline ylc3 & 0.2132 & 0.0000 & 0.0000 & 0.0000 & 0.9370 & 0.1513 & 0.1151 \\
\hline ylc4 & 0.0443 & 0.0000 & 0.0000 & 0.0000 & 0.0000 & 0.7395 & 0.0255 \\
\hline $\mathrm{n}$ & 1961 & 6965 & 98 & 397 & 408 & 124 & 9953 \\
\hline
\end{tabular}

Note: Statistics in the first column (mid deal) refer to player-seasons in which the player has not entered into a new contract. All other columns refer to information for the player-season in which the player has entered into a contract. 
Table 2b: Summary statistics by deal status, pitchers

\begin{tabular}{|c|c|c|c|c|c|c|c|}
\hline & mid deal & 1 & $1+1$ & 2 & $3-4$ & $5+$ & All \\
\hline age & 31.87 & 27.64 & 33.16 & 31.44 & 29.94 & 29.19 & 28.55 \\
\hline age23u & 0.008 & 0.124 & 0.012 & 0.012 & 0.032 & 0.063 & 0.098 \\
\hline age 2425 & 0.024 & 0.207 & 0.012 & 0.034 & 0.075 & 0.000 & 0.166 \\
\hline age2629 & 0.223 & 0.405 & 0.136 & 0.281 & 0.338 & 0.531 & 0.368 \\
\hline age3033 & 0.427 & 0.175 & 0.420 & 0.394 & 0.425 & 0.344 & 0.233 \\
\hline age3437 & 0.251 & 0.065 & 0.222 & 0.220 & 0.114 & 0.063 & 0.102 \\
\hline age38up & 0.067 & 0.025 & 0.198 & 0.058 & 0.016 & 0.000 & 0.033 \\
\hline debutyear & 1989.2 & 1991.8 & 1989.8 & 1989.9 & 1990.0 & 1987.6 & 1991.6 \\
\hline dealyr & 1997.0 & 1996.2 & 2000.0 & 1998.3 & 1997.4 & 1994.8 & 1996.4 \\
\hline deallength & 2.836 & 1.000 & 1.000 & 2.000 & 3.328 & 5.375 & 1.168 \\
\hline yrsin & 2.616 & 1.000 & 1.000 & 1.031 & 1.133 & 1.594 & 1.010 \\
\hline yrsleft & 0.6302 & 0.0000 & 0.0000 & 0.9694 & 2.1948 & 3.7813 & 0.1577 \\
\hline era & 4.263 & 4.858 & 4.390 & 4.425 & 4.080 & 3.890 & 4.716 \\
\hline whip & 1.373 & 1.504 & 1.385 & 1.406 & 1.368 & 1.306 & 1.474 \\
\hline obp_a & 0.328 & 0.345 & 0.330 & 0.332 & 0.325 & 0.318 & 0.341 \\
\hline $\operatorname{slg} \_a$ & 0.412 & 0.424 & 0.416 & 0.416 & 0.403 & 0.386 & 0.421 \\
\hline ops_a & 0.739 & 0.770 & 0.746 & 0.748 & 0.728 & 0.704 & 0.762 \\
\hline rc27_a & 3.735 & 4.060 & 3.763 & 3.814 & 3.587 & 3.357 & 3.979 \\
\hline k9 & 6.681 & 6.263 & 6.610 & 6.513 & 6.872 & 6.711 & 6.362 \\
\hline $\exp$ & 9.414 & 4.402 & 10.272 & 8.431 & 7.451 & 7.781 & 5.482 \\
\hline salary & 4094559 & 668495 & 2121285 & 2102118 & 3175973 & 4488289 & 1350844 \\
\hline isal & 2.303 & 0.517 & 1.106 & 1.296 & 2.097 & 3.028 & 0.885 \\
\hline Insal & 14.91 & 12.77 & 14.13 & 14.25 & 14.64 & 14.82 & 13.23 \\
\hline Inisal & 0.632 & -1.258 & -0.261 & 0.026 & 0.488 & 0.931 & -0.847 \\
\hline teamsalhi & 0.326 & 0.174 & 0.235 & 0.229 & 0.338 & 0.313 & 0.206 \\
\hline teamsallo & 0.102 & 0.250 & 0.111 & 0.159 & 0.091 & 0.063 & 0.217 \\
\hline q1 & 0.0411 & 0.2486 & 0.0864 & 0.0734 & 0.0521 & 0.0313 & 0.2282 \\
\hline $\mathrm{q} 2$ & 0.1571 & 0.2103 & 0.1481 & 0.1774 & 0.2085 & 0.2500 & 0.2081 \\
\hline $\mathrm{q} 3$ & 0.2179 & 0.1956 & 0.1235 & 0.2049 & 0.2280 & 0.2188 & 0.1968 \\
\hline $\mathrm{q} 4$ & 0.2664 & 0.1793 & 0.3086 & 0.2538 & 0.2443 & 0.2813 & 0.1879 \\
\hline $\mathrm{q} 5$ & 0.3174 & 0.1662 & 0.3333 & 0.2905 & 0.2671 & 0.2188 & 0.1790 \\
\hline dlc & 3.775 & 1.000 & 2.000 & 3.000 & 4.000 & 5.000 & 1.253 \\
\hline dops_a & 0.0041 & 0.0017 & 0.0059 & 0.0250 & 0.0275 & 0.0159 & 0.0164 \\
\hline ddops_a & 0.5732 & 1.0000 & 1.0000 & 0.0235 & 0.0140 & 0.0345 & 0.0048 \\
\hline ylc1 & 0.2767 & 0.0000 & 0.0000 & 0.9765 & 0.0281 & 0.0690 & 0.8126 \\
\hline ylc2 & 0.1338 & 0.0000 & 0.0000 & 0.0000 & 0.9579 & 0.1724 & 0.1061 \\
\hline ylc3 & 0.0163 & 0.0000 & 0.0000 & 0.0000 & 0.0000 & 0.7241 & 0.0745 \\
\hline ylc4 & 3.776 & 1.000 & 2.000 & 3.000 & 4.000 & 5.000 & 0.0068 \\
\hline $\mathrm{n}$ & 1217 & 6316 & 81 & 327 & 308 & 32 & 8281 \\
\hline
\end{tabular}

Note: Statistics in the first column (mid deal) refer to player-seasons in which the player has not entered into a new contract. All other columns refer to information for the player-season in which the player has entered into a contract. 
Table 3a: Contracts, by deal length and age group, batters

\begin{tabular}{|l|l|l|l|l|l|l|}
\hline & 1 & $1+1$ & 2 & $3-4$ & $5+$ & All \\
\hline$<23$ & 785 & 0 & 1 & 22 & 7 & 815 \\
\hline $24-25$ & 1,374 & 1 & 8 & 31 & 17 & 1,431 \\
\hline $26-29$ & 2,826 & 18 & 101 & 169 & 52 & 3,166 \\
\hline $30-33$ & 1,254 & 36 & 174 & 149 & 37 & 1,650 \\
\hline $34-37$ & 551 & 35 & 103 & 35 & 11 & 735 \\
\hline $38 \& u p$ & 175 & 8 & 10 & 2 & 0 & 195 \\
\hline Total & 6,965 & 98 & 397 & 408 & 124 & 7,992 \\
\hline
\end{tabular}

Row percentages:

\begin{tabular}{|l|l|l|l|l|l|l|}
\hline & 1 & $1+1$ & 2 & $3-4$ & $5+$ & All \\
\hline$<23$ & 96.32 & 0.00 & 0.12 & 2.70 & 0.86 & 100.00 \\
\hline $24-25$ & 96.02 & 0.07 & 0.56 & 2.17 & 1.19 & 100.00 \\
\hline $26-29$ & 89.26 & 0.57 & 3.19 & 5.34 & 1.64 & 100.00 \\
\hline $30-33$ & 76.00 & 2.18 & 10.55 & 9.03 & 2.24 & 100.00 \\
\hline $34-37$ & 74.97 & 4.76 & 14.01 & 4.76 & 1.50 & 100.00 \\
\hline $38 \& u p$ & 89.74 & 4.10 & 5.13 & 1.03 & 0.00 & 100.00 \\
\hline Total & 87.15 & 1.23 & 4.97 & 5.11 & 1.55 & 100.00 \\
\hline
\end{tabular}

Column percentages:

\begin{tabular}{|l|l|l|l|l|l|l|}
\hline & 1 & $1+1$ & 2 & $3-4$ & $5+$ & All \\
\hline$<23$ & 11.27 & 0.00 & 0.25 & 5.39 & 5.65 & 10.20 \\
\hline $24-25$ & 19.73 & 1.02 & 2.02 & 7.60 & 13.71 & 17.91 \\
\hline $26-29$ & 40.57 & 18.37 & 25.44 & 41.42 & 41.94 & 39.61 \\
\hline $30-33$ & 18.00 & 36.73 & 43.83 & 36.52 & 29.84 & 20.65 \\
\hline $34-37$ & 7.91 & 35.71 & 25.94 & 8.58 & 8.87 & 9.20 \\
\hline $38 \& u p$ & 2.51 & 8.16 & 2.52 & 0.49 & 0.00 & 2.44 \\
\hline Total & 100.00 & 100.00 & 100.00 & 100.00 & 100.00 & 100.00 \\
\hline
\end{tabular}

Note: The null hypothesis of independence between deal length and age group is rejected at the $1 \%$ significance level $\left(\chi^{2}=636.9, p=0.000\right)$. 
Table 3b: Contracts, by deal length and age group, pitchers

\begin{tabular}{|l|l|l|l|l|l|l|}
\hline & 1 & $1+1$ & 2 & $3-4$ & $5+$ & All \\
\hline$<23$ & 781 & 1 & 4 & 10 & 2 & 798 \\
\hline $24-25$ & 1,307 & 1 & 11 & 23 & 0 & 1,342 \\
\hline $26-29$ & 2,556 & 11 & 92 & 104 & 17 & 2,780 \\
\hline $30-33$ & 1,105 & 34 & 129 & 131 & 11 & 1,410 \\
\hline $34-37$ & 411 & 18 & 72 & 35 & 2 & 538 \\
\hline $38 \& u p$ & 156 & 16 & 19 & 5 & 0 & 196 \\
\hline Total & 6,316 & 81 & 327 & 308 & 32 & 7,064 \\
\hline
\end{tabular}

Row percentages:

\begin{tabular}{|l|l|l|l|l|l|l|}
\hline & 1 & $1+1$ & 2 & $3-4$ & $5+$ & All \\
\hline$<23$ & 97.87 & 0.13 & 0.50 & 1.25 & 0.25 & 100.00 \\
\hline $24-25$ & 97.39 & 0.07 & 0.82 & 1.71 & 0.00 & 100.00 \\
\hline $26-29$ & 91.94 & 0.40 & 3.31 & 3.74 & 0.61 & 100.00 \\
\hline $30-33$ & 78.37 & 2.41 & 9.15 & 9.29 & 0.78 & 100.00 \\
\hline $34-37$ & 76.39 & 3.35 & 13.38 & 6.51 & 0.37 & 100.00 \\
\hline $38 \& u p$ & 79.59 & 8.16 & 9.69 & 2.55 & 0.00 & 100.00 \\
\hline Total & 89.41 & 1.15 & 4.63 & 4.36 & 0.45 & 100.00 \\
\hline
\end{tabular}

Column percentages:

\begin{tabular}{|l|l|l|l|l|l|l|}
\hline & 1 & $1+1$ & 2 & $3-4$ & $5+$ & All \\
\hline$<23$ & 12.37 & 1.23 & 1.22 & 3.25 & 6.25 & 11.30 \\
\hline $24-25$ & 20.69 & 1.23 & 3.36 & 7.47 & 0.00 & 19.00 \\
\hline $26-29$ & 40.47 & 13.58 & 28.13 & 33.77 & 53.13 & 39.35 \\
\hline $30-33$ & 17.50 & 41.98 & 39.45 & 42.53 & 34.38 & 19.96 \\
\hline $34-37$ & 6.51 & 22.22 & 22.02 & 11.36 & 6.25 & 7.62 \\
\hline $38 \&$ up & 2.47 & 19.75 & 5.81 & 1.62 & 0.00 & 2.77 \\
\hline Total & 100.00 & 100.00 & 100.00 & 100.00 & 100.00 & 100.00 \\
\hline
\end{tabular}

Note: The null hypothesis of independence between deal length and age group is rejected at the $1 \%$ significance level $\left(\chi^{2}=594.5, p=0.000\right)$. 
Table 4a: Contracts, by deal length and defensive position, batters

\begin{tabular}{|l|l|l|l|l|l|l|}
\hline & 1 & $1+1$ & 2 & $3-4$ & $5+$ & All \\
\hline 1B & 771 & 13 & 63 & 51 & 20 & 918 \\
\hline 2B & 824 & 14 & 41 & 44 & 8 & 931 \\
\hline 3B & 815 & 10 & 41 & 52 & 14 & 932 \\
\hline C & 1,148 & 19 & 77 & 52 & 10 & 1,306 \\
\hline DH & 54 & 2 & 3 & 4 & 0 & 63 \\
\hline OF & 2,616 & 31 & 141 & 156 & 57 & 3,001 \\
\hline SS & 737 & 9 & 31 & 49 & 15 & 841 \\
\hline Total & 6,965 & 98 & 397 & 408 & 124 & 7,992 \\
\hline
\end{tabular}

Row percentages:

\begin{tabular}{|l|l|l|l|l|l|l|}
\hline & 1 & $1+1$ & 2 & $3-4$ & $5+$ & All \\
\hline 1B & 83.99 & 1.42 & 6.86 & 5.56 & 2.18 & 100.00 \\
\hline 2B & 88.51 & 1.50 & 4.40 & 4.73 & 0.86 & 100.00 \\
\hline 3B & 87.45 & 1.07 & 4.40 & 5.58 & 1.50 & 100.00 \\
\hline C & 87.90 & 1.45 & 5.90 & 3.98 & 0.77 & 100.00 \\
\hline DH & 85.71 & 3.17 & 4.76 & 6.35 & 0.00 & 100.00 \\
\hline OF & 87.17 & 1.03 & 4.70 & 5.20 & 1.90 & 100.00 \\
\hline SS & 87.63 & 1.07 & 3.69 & 5.83 & 1.78 & 100.00 \\
\hline Total & 87.15 & 1.23 & 4.97 & 5.11 & 1.55 & 100.00 \\
\hline
\end{tabular}

Column percentages

\begin{tabular}{|l|l|l|l|l|l|l|}
\hline & 1 & $1+1$ & 2 & $3-4$ & $5+$ & All \\
\hline 1B & 11.07 & 13.27 & 15.87 & 12.50 & 16.13 & 11.49 \\
\hline 2B & 11.83 & 14.29 & 10.33 & 10.78 & 6.45 & 11.65 \\
\hline 3B & 11.70 & 10.20 & 10.33 & 12.75 & 11.29 & 11.66 \\
\hline C & 16.48 & 19.39 & 19.40 & 12.75 & 8.06 & 16.34 \\
\hline DH & 0.78 & 2.04 & 0.76 & 0.98 & 0.00 & 0.79 \\
\hline OF & 37.56 & 31.63 & 35.52 & 38.24 & 45.97 & 37.55 \\
\hline SS & 10.58 & 9.18 & 7.81 & 12.01 & 12.10 & 10.52 \\
\hline Total & 100.00 & 100.00 & 100.00 & 100.00 & 100.00 & 100.00 \\
\hline
\end{tabular}

Note: The null hypothesis of independence between deal length and defensive positions is rejected at the 5\% significance level $\left(\chi^{2}=38.72, p=0.029\right)$. 
Table 4b: Contracts, by deal length and defensive position, pitchers

\begin{tabular}{|l|l|l|l|l|l|l|}
\hline & $1 \mathrm{yr}$ & $1+1$ & $2 \mathrm{yr}$ & $3-4$ & $5+$ & Total \\
\hline LHC & 67 & 3 & 11 & 14 & 1 & 96 \\
\hline LHP & 1,087 & 13 & 62 & 24 & 0 & 1,186 \\
\hline LHS & 675 & 7 & 38 & 68 & 9 & 797 \\
\hline RHC & 557 & 9 & 52 & 41 & 5 & 664 \\
\hline RHP & 2,194 & 22 & 73 & 30 & 0 & 2,319 \\
\hline RHS & 1,736 & 27 & 91 & 131 & 17 & 2,002 \\
\hline Total & 6,316 & 81 & 327 & 308 & 32 & 7,064 \\
\hline
\end{tabular}

Row percentages:

\begin{tabular}{|l|l|l|l|l|l|l|}
\hline & $1 \mathrm{yr}$ & $1+1$ & $2 \mathrm{yr}$ & $3-4$ & $5+$ & Total \\
\hline LHC & 69.79 & 3.13 & 11.46 & 14.58 & 1.04 & 100.00 \\
\hline LHP & 91.65 & 1.10 & 5.23 & 2.02 & 0.00 & 100.00 \\
\hline LHS & 84.69 & 0.88 & 4.77 & 8.53 & 1.13 & 100.00 \\
\hline RHC & 83.89 & 1.36 & 7.83 & 6.17 & 0.75 & 100.00 \\
\hline RHP & 94.61 & 0.95 & 3.15 & 1.29 & 0.00 & 100.00 \\
\hline RHS & 86.71 & 1.35 & 4.55 & 6.54 & 0.85 & 100.00 \\
\hline Total & 89.41 & 1.15 & 4.63 & 4.36 & 0.45 & 100.00 \\
\hline
\end{tabular}

Column percentages:

\begin{tabular}{|l|l|l|l|l|l|l|}
\hline & $1 \mathrm{yr}$ & $1+1$ & $2 \mathrm{yr}$ & $3-4$ & $5+$ & Total \\
\hline LHC & 1.06 & 3.70 & 3.36 & 4.55 & 3.13 & 1.36 \\
\hline LHP & 17.21 & 16.05 & 18.96 & 7.79 & 0.00 & 16.79 \\
\hline LHS & 10.69 & 8.64 & 11.62 & 22.08 & 28.13 & 11.28 \\
\hline RHC & 8.82 & 11.11 & 15.90 & 13.31 & 15.63 & 9.40 \\
\hline RHP & 34.74 & 27.16 & 22.32 & 9.74 & 0.00 & 32.83 \\
\hline RHS & 27.49 & 33.33 & 27.83 & 42.53 & 53.13 & 28.34 \\
\hline Total & 100.00 & 100.00 & 100.00 & 100.00 & 100.00 & 100.00 \\
\hline
\end{tabular}

Note: The null hypothesis of independence between deal length and defensive positions is rejected at the $5 \%$ significance level $\left(\chi^{2}=239.1, p=0.000\right)$. 
Table 5a: Contracts, by deal length and CBA regime, batters

\begin{tabular}{|l|l|l|l|l|l|l|}
\hline & 1 & $1+1$ & 2 & $3-4$ & $5+$ & Total \\
\hline $1981-85$ & 208 & 1 & 18 & 43 & 37 & 307 \\
\hline $1986-89$ & 1,253 & 7 & 37 & 28 & 0 & 1,325 \\
\hline $1990-94$ & 1,660 & 6 & 71 & 101 & 15 & 1,853 \\
\hline $1995-01$ & 2,269 & 37 & 164 & 131 & 37 & 2,638 \\
\hline $2002-06$ & 1,335 & 34 & 87 & 83 & 26 & 1,565 \\
\hline 2007 & 240 & 13 & 20 & 22 & 9 & 304 \\
\hline Total & 6,965 & 98 & 397 & 408 & 124 & 7,992 \\
\hline
\end{tabular}

Row percentages:

\begin{tabular}{|l|l|l|l|l|l|l|}
\hline & 1 & $1+1$ & 2 & $3-4$ & $5+$ & Total \\
\hline $1981-85$ & 67.75 & 0.33 & 5.86 & 14.01 & 12.05 & 100.00 \\
\hline $1986-89$ & 94.57 & 0.53 & 2.79 & 2.11 & 0.00 & 100.00 \\
\hline $1990-94$ & 89.58 & 0.32 & 3.83 & 5.45 & 0.81 & 100.00 \\
\hline $1995-01$ & 86.01 & 1.40 & 6.22 & 4.97 & 1.40 & 100.00 \\
\hline $2002-06$ & 85.30 & 2.17 & 5.56 & 5.30 & 1.66 & 100.00 \\
\hline 2007 & 78.95 & 4.28 & 6.58 & 7.24 & 2.96 & 100.00 \\
\hline Total & 87.15 & 1.23 & 4.97 & 5.11 & 1.55 & 100.00 \\
\hline
\end{tabular}

Column percentages:

\begin{tabular}{|l|l|l|l|l|l|l|}
\hline & 1 & $1+1$ & 2 & $3-4$ & $5+$ & Total \\
\hline $1981-85$ & 2.99 & 1.02 & 4.53 & 10.54 & 29.84 & 3.84 \\
\hline $1986-89$ & 17.99 & 7.14 & 9.32 & 6.86 & 0.00 & 16.58 \\
\hline $1990-94$ & 23.83 & 6.12 & 17.88 & 24.75 & 12.10 & 23.19 \\
\hline $1995-01$ & 32.58 & 37.76 & 41.31 & 32.11 & 29.84 & 33.01 \\
\hline $2002-06$ & 19.17 & 34.69 & 21.91 & 20.34 & 20.97 & 19.58 \\
\hline 2007 & 3.45 & 13.27 & 5.04 & 5.39 & 7.26 & 3.80 \\
\hline Total & 100.00 & 100.00 & 100.00 & 100.00 & 100.00 & 100.00 \\
\hline
\end{tabular}

Note: The null hypothesis of independence between deal length and defensive positions is rejected at the $1 \%$ significance level $\left(\chi^{2}=433.8, p=0.000\right)$. 
Table 5b: Contracts, by deal length and bargaining era, pitchers

\begin{tabular}{|l|l|l|l|l|l|l|}
\hline & 1 & $1+1$ & 2 & $3-4$ & $5+$ & Total \\
\hline $1981-85$ & 171 & 1 & 9 & 22 & 12 & 215 \\
\hline $1986-89$ & 954 & 4 & 29 & 19 & 0 & 1,006 \\
\hline $1990-94$ & 1,430 & 9 & 42 & 63 & 2 & 1,546 \\
\hline $1995-01$ & 2,206 & 28 & 139 & 111 & 9 & 2,493 \\
\hline $2002-06$ & 1,292 & 29 & 93 & 69 & 5 & 1,488 \\
\hline 2007 & 263 & 10 & 15 & 24 & 4 & 316 \\
\hline Total & 6,316 & 81 & 327 & 308 & 32 & 7,064 \\
\hline
\end{tabular}

Row percentages:

\begin{tabular}{|l|l|l|l|l|l|l|}
\hline & 1 & $1+1$ & 2 & $3-4$ & $5+$ & Total \\
\hline $1981-85$ & 79.53 & 0.47 & 4.19 & 10.23 & 5.58 & 100.00 \\
\hline $1986-89$ & 94.83 & 0.40 & 2.88 & 1.89 & 0.00 & 100.00 \\
\hline $1990-94$ & 92.50 & 0.58 & 2.72 & 4.08 & 0.13 & 100.00 \\
\hline $1995-01$ & 88.49 & 1.12 & 5.58 & 4.45 & 0.36 & 100.00 \\
\hline $2002-06$ & 86.83 & 1.95 & 6.25 & 4.64 & 0.34 & 100.00 \\
\hline $2007-$ & 83.23 & 3.16 & 4.75 & 7.59 & 1.27 & 100.00 \\
\hline Total & 89.41 & 1.15 & 4.63 & 4.36 & 0.45 & 100.00 \\
\hline
\end{tabular}

Column percentages:

\begin{tabular}{|l|l|l|l|l|l|l|}
\hline & 1 & $1+1$ & 2 & $3-4$ & $5+$ & Total \\
\hline $1981-85$ & 2.71 & 1.23 & 2.75 & 7.14 & 37.50 & 3.04 \\
\hline $1986-89$ & 15.10 & 4.94 & 8.87 & 6.17 & 0.00 & 14.24 \\
\hline $1990-94$ & 22.64 & 11.11 & 12.84 & 20.45 & 6.25 & 21.89 \\
\hline $1995-01$ & 34.93 & 34.57 & 42.51 & 36.04 & 28.13 & 35.29 \\
\hline $2002-06$ & 20.46 & 35.80 & 28.44 & 22.40 & 15.63 & 21.06 \\
\hline $2007-$ & 4.16 & 12.35 & 4.59 & 7.79 & 12.50 & 4.47 \\
\hline Total & 100.00 & 100.00 & 100.00 & 100.00 & 100.00 & 100.00 \\
\hline
\end{tabular}

Note: The null hypothesis of independence between deal length and defensive positions is rejected at the $1 \%$ significance level $\left(\chi^{2}=249.6, p=0.000\right)$. 
Table 6: Contracts, by years remaining on contract and team payroll category Panel A: Batters

\begin{tabular}{|l|l|l|l|l|l|}
\hline & 0 & 1 & $2-3$ & $4+$ & Total \\
\hline Low & 1,879 & 123 & 100 & 15 & 2,117 \\
\hline Mid & 4,618 & 554 & 469 & 87 & 5,728 \\
\hline High & 1,572 & 254 & 216 & 66 & 2,108 \\
\hline Total & 8,069 & 931 & 785 & 168 & 9,953 \\
\hline
\end{tabular}

Row percentages:

\begin{tabular}{|l|l|l|l|l|l|}
\hline & 0 & 1 & $2-3$ & $4+$ & Total \\
\hline Low & 88.76 & 5.81 & 4.72 & 0.71 & 100.00 \\
\hline Mid & 80.62 & 9.67 & 8.19 & 1.52 & 100.00 \\
\hline High & 74.57 & 12.05 & 10.25 & 3.13 & 100.00 \\
\hline Total & 81.07 & 9.35 & 7.89 & 1.69 & 100.00 \\
\hline
\end{tabular}

Column percentages:

\begin{tabular}{|l|l|l|l|l|l|}
\hline & 0 & 1 & $2-3$ & $4+$ & Total \\
\hline Low & 23.29 & 13.21 & 12.74 & 8.93 & 21.27 \\
\hline Mid & 57.23 & 59.51 & 59.75 & 51.79 & 57.55 \\
\hline High & 19.48 & 27.28 & 27.52 & 39.29 & 21.18 \\
\hline Total & 100.00 & 100.00 & 100.00 & 100.00 & 100.00 \\
\hline
\end{tabular}

Panel B: Pitchers

\begin{tabular}{|l|l|l|l|l|l|}
\hline & 0 & 1 & $2-3$ & $4+$ & Total \\
\hline Low & 1,673 & 84 & 35 & 1 & 1,793 \\
\hline Mid & 4,117 & 383 & 258 & 26 & 4,784 \\
\hline High & 1,333 & 194 & 162 & 15 & 1,704 \\
\hline Total & 7,123 & 661 & 455 & 42 & 8,281 \\
\hline
\end{tabular}

Row percentages:

\begin{tabular}{|l|l|l|l|l|l|}
\hline & 0 & 1 & $2-3$ & $4+$ & Total \\
\hline Low & 93.31 & 4.68 & 1.95 & 0.06 & 100.00 \\
\hline Mid & 86.06 & 8.01 & 5.39 & 0.54 & 100.00 \\
\hline High & 78.23 & 11.38 & 9.51 & 0.88 & 100.00 \\
\hline Total & 86.02 & 7.98 & 5.49 & 0.51 & 100.00 \\
\hline
\end{tabular}

Column percentages:

\begin{tabular}{|l|l|l|l|l|l|}
\hline & 0 & 1 & $2-3$ & $4+$ & Total \\
\hline Low & 23.49 & 12.71 & 7.69 & 2.38 & 21.65 \\
\hline Mid & 57.80 & 57.94 & 56.70 & 61.90 & 57.77 \\
\hline High & 18.71 & 29.35 & 35.60 & 35.71 & 20.58 \\
\hline Total & 100.00 & 100.00 & 100.00 & 100.00 & 100.00 \\
\hline
\end{tabular}

Note: The null hypothesis of independence between years remaining and salary category is rejected at the $1 \%$ level for both batters $\left(\chi^{2}=153.4, p=0.000\right)$ and pitchers $\left(\chi^{2}=175.2\right.$, $\mathrm{p}=0.000$ ). Low (high) refers to the 6 teams with lowest (highest) opening day payroll. 
Table 7a: Contracts, by years remaining on contract and bargaining era, batters

\begin{tabular}{|l|l|l|l|l|l|}
\hline & 0 & 1 & $2-3$ & $4+$ & Total \\
\hline $1981-85$ & 240 & 29 & 38 & 11 & 318 \\
\hline $1986-89$ & 1,362 & 103 & 73 & 6 & 1,544 \\
\hline $1990-94$ & 1,858 & 183 & 156 & 18 & 2,215 \\
\hline $1995-01$ & 2,676 & 351 & 277 & 47 & 3,351 \\
\hline $2002-06$ & 1,629 & 217 & 194 & 70 & 2,110 \\
\hline $2007-$ & 304 & 48 & 47 & 16 & 415 \\
\hline Total & 8,069 & 931 & 785 & 168 & 9,953 \\
\hline
\end{tabular}

Row percentages:

\begin{tabular}{|l|l|l|l|l|l|}
\hline & 0 & 1 & $2-3$ & $4+$ & Total \\
\hline $1981-85$ & 75.47 & 9.12 & 11.95 & 3.46 & 100.00 \\
\hline $1986-89$ & 88.21 & 6.67 & 4.73 & 0.39 & 100.00 \\
\hline $1990-94$ & 83.88 & 8.26 & 7.04 & 0.81 & 100.00 \\
\hline $1995-01$ & 79.86 & 10.47 & 8.27 & 1.40 & 100.00 \\
\hline $2002-06$ & 77.20 & 10.28 & 9.19 & 3.32 & 100.00 \\
\hline $2007-$ & 73.25 & 11.57 & 11.33 & 3.86 & 100.00 \\
\hline Total & 81.07 & 9.35 & 7.89 & 1.69 & 100.00 \\
\hline
\end{tabular}

Column percentages:

\begin{tabular}{|l|l|l|l|l|l|}
\hline & 0 & 1 & $2-3$ & $4+$ & Total \\
\hline $1981-85$ & 2.97 & 3.11 & 4.84 & 6.55 & 3.20 \\
\hline $1986-89$ & 16.88 & 11.06 & 9.30 & 3.57 & 15.51 \\
\hline $1990-94$ & 23.03 & 19.66 & 19.87 & 10.71 & 22.25 \\
\hline $1995-01$ & 33.16 & 37.70 & 35.29 & 27.98 & 33.67 \\
\hline $2002-06$ & 20.19 & 23.31 & 24.71 & 41.67 & 21.20 \\
\hline $2007-$ & 3.77 & 5.16 & 5.99 & 9.52 & 4.17 \\
\hline Total & 100.00 & 100.00 & 100.00 & 100.00 & 100.00 \\
\hline
\end{tabular}

Note: The null hypothesis of independence between years remaining on contract and bargaining era is rejected at the $1 \%$ significance level $\left(\chi^{2}=161.4, p=0.000\right)$. 
Table 7b: Contracts, by years remaining on contract and bargaining era, pitchers

\begin{tabular}{|l|l|l|l|l|l|}
\hline & 0 & 1 & $2-3$ & $4+$ & Total \\
\hline $1981-85$ & 183 & 15 & 17 & 5 & 220 \\
\hline $1986-89$ & 1,022 & 58 & 35 & 2 & 1,117 \\
\hline $1990-94$ & 1,552 & 113 & 90 & 3 & 1,758 \\
\hline $1995-01$ & 2,489 & 252 & 153 & 13 & 2,907 \\
\hline $2002-06$ & 1,564 & 187 & 121 & 13 & 1,885 \\
\hline $2007-$ & 313 & 36 & 39 & 6 & 394 \\
\hline Total & 7,123 & 661 & 455 & 42 & 8,281 \\
\hline
\end{tabular}

Row percentages:

\begin{tabular}{|l|l|l|l|l|l|}
\hline & 0 & 1 & $2-3$ & $4+$ & Total \\
\hline $1981-85$ & 83.18 & 6.82 & 7.73 & 2.27 & 100.00 \\
\hline $1986-89$ & 91.50 & 5.19 & 3.13 & 0.18 & 100.00 \\
\hline $1990-94$ & 88.28 & 6.43 & 5.12 & 0.17 & 100.00 \\
\hline $1995-01$ & 85.62 & 8.67 & 5.26 & 0.45 & 100.00 \\
\hline $2002-06$ & 82.97 & 9.92 & 6.42 & 0.69 & 100.00 \\
\hline $2007-$ & 79.44 & 9.14 & 9.90 & 1.52 & 100.00 \\
\hline Total & 86.02 & 7.98 & 5.49 & 0.51 & 100.00 \\
\hline
\end{tabular}

Column percentages:

\begin{tabular}{|l|l|l|l|l|l|}
\hline & 0 & 1 & $2-3$ & $4+$ & Total \\
\hline $1981-85$ & 2.57 & 2.27 & 3.74 & 11.90 & 2.66 \\
\hline $1986-89$ & 14.35 & 8.77 & 7.69 & 4.76 & 13.49 \\
\hline $1990-94$ & 21.79 & 17.10 & 19.78 & 7.14 & 21.23 \\
\hline $1995-01$ & 34.94 & 38.12 & 33.63 & 30.95 & 35.10 \\
\hline $2002-06$ & 21.96 & 28.29 & 26.59 & 30.95 & 22.76 \\
\hline $2007-$ & 4.39 & 5.45 & 8.57 & 14.29 & 4.76 \\
\hline Total & 100.00 & 100.00 & 100.00 & 100.00 & 100.00 \\
\hline
\end{tabular}

Note: The null hypothesis of independence between years remaining on contract and bargaining era is rejected at the $1 \%$ significance level $\left(\chi^{2}=97.22, p=0.000\right)$. 
Table 8: Fraction of player-season in final year of contract by performance quintile,

Panel A: Batters

\begin{tabular}{|l|l|l|}
\hline Performance Quintile & Observations & Fraction \\
\hline q1 & 1890 & 0.922 \\
\hline q2 & 1880 & 0.882 \\
\hline q3 & 1880 & 0.827 \\
\hline q4 & 1890 & 0.750 \\
\hline q5 & 1873 & 0.621 \\
\hline no quintile & 540 & 0.985 \\
\hline Total & 9953 & 0.811 \\
\hline
\end{tabular}

Panel B: Pitchers

\begin{tabular}{|l|l|l|}
\hline Performance Quintile & Observations & Fraction \\
\hline 1 & 1591 & 0.965 \\
\hline 2 & 1596 & 0.873 \\
\hline 3 & 1594 & 0.837 \\
\hline 4 & 1593 & 0.813 \\
\hline 5 & 1595 & 0.787 \\
\hline no quintile & 312 & 0.997 \\
\hline Total & 8281 & 0.860 \\
\hline
\end{tabular}

Note: The criteria used for selecting performance quintiles for batters (pitchers) is based on each player's best season with at least 130 plate appearances (batters faced), as measured by OPS (OPS against).

Players without a qualifying season are not assigned a quintile. 
Table 9: Average change in OPS (OPS against) by age and performance quintile

Panel A: Batters

\begin{tabular}{|l|l|l|l|l|l|}
\hline & $\mathrm{q} 1$ & $\mathrm{q} 2$ & $\mathrm{q} 3$ & $\mathrm{q} 4$ & $\mathrm{q} 5$ \\
\hline$<23$ & -0.0008 & -0.0004 & 0.0117 & 0.0122 & 0.0412 \\
\hline $24-25$ & -0.0019 & 0.0019 & 0.0089 & 0.0107 & 0.0257 \\
\hline $26-29$ & -0.0116 & -0.0029 & -0.0072 & 0.0036 & 0.0033 \\
\hline $30-33$ & -0.0145 & -0.0123 & -0.0115 & -0.0106 & -0.0114 \\
\hline $34-37$ & -0.0148 & -0.0119 & -0.0267 & -0.0115 & -0.0193 \\
\hline 38 up & -0.0284 & -0.0319 & -0.0083 & -0.0311 & -0.0361 \\
\hline
\end{tabular}

Panel B: Pitchers

\begin{tabular}{|l|l|l|l|l|l|}
\hline & $\mathrm{q} 1$ & $\mathrm{q} 2$ & $\mathrm{q} 3$ & $\mathrm{q} 4$ & $\mathrm{q} 5$ \\
\hline$<23$ & 0.0245 & 0.0071 & 0.0046 & -0.0133 & 0.0018 \\
\hline $24-25$ & 0.0090 & 0.0124 & 0.0005 & -0.0006 & -0.0128 \\
\hline $26-29$ & 0.0183 & 0.0134 & 0.0117 & 0.0084 & 0.0074 \\
\hline $30-33$ & 0.0241 & 0.0198 & 0.0119 & 0.0150 & 0.0077 \\
\hline $34-37$ & 0.0236 & 0.0071 & 0.0194 & 0.0178 & 0.0172 \\
\hline $38 \&$ up & 0.0121 & 0.0182 & 0.0023 & 0.0183 & 0.0141 \\
\hline
\end{tabular}


Table 10: OLS regressions of unpredictable change in performance

Panel A: Batters

Dependent variable: dops

\begin{tabular}{|l|r|r|r|r|l|l|r|}
\hline Variable & \multicolumn{1}{l|}{ coef. } & std. error & $\mathrm{t}$ & \multicolumn{1}{l|}{ Prob $>\mathrm{t}$} & & $\mathrm{N}$ & 6558 \\
\hline ylc2 & -0.0052 & 0.0034 & -1.53 & 0.126 & & $\mathrm{~F}$ & 6.04 \\
\hline ylc3 & -0.0094 & 0.0033 & -2.80 & 0.005 & & Prob $>\mathrm{F}$ & 0.0004 \\
\hline ylc4 & -0.0212 & 0.0063 & -3.35 & 0.001 & & R-squared & 0.0028 \\
\hline cons & 0.0013 & 0.0014 & 0.90 & 0.370 & & Adj. R-squared & 0.0023 \\
\hline
\end{tabular}

Note: observations are weighted by plate appearances.

\section{Panel B: Pitchers}

Dependent variable: dops_a

\begin{tabular}{|l|r|r|r|r|l|l|r|}
\hline Variable & \multicolumn{1}{c|}{ coef } & std error & \multicolumn{1}{l|}{$\mathrm{t}$} & \multicolumn{1}{|l|}{ Prob>t } & & $\mathrm{N}$ & 5719 \\
\hline ylc2 & 0.0066 & 0.0038 & 1.76 & 0.078 & & F & 6.30 \\
\hline ylc3 & 0.0162 & 0.0039 & 4.12 & 0.000 & & Prob > F & 0.0003 \\
\hline ylc4 & 0.0083 & 0.0110 & 0.75 & 0.454 & & R-squared & 0.0033 \\
\hline cons & -0.0002 & 0.0013 & -0.16 & 0.876 & & Adj. R-squared & 0.0028 \\
\hline
\end{tabular}

Note: observations are weighted by batters faced. 
Table 11: Mean unexpected difference in OPS (OPS against) by deal length and years remaining on contract

Panel A: Batters

\begin{tabular}{|c|c|c|c|c|}
\hline & 0 yrs & $1 \mathrm{yr}$ & $2-3$ & $4+$ \\
\hline $1 \mathrm{yr}$ & 0.0013 & -- & -- & -- \\
\hline $1+1$ & 0.0205 & -- & -- & -- \\
\hline $2 \mathrm{yrs}$ & 0.0112 & -0.0265 & -- & -- \\
\hline $3-4$ & -0.0043 & 0.0133 & -0.0151 & -- \\
\hline $5+$ & -0.0145 & 0.0033 & 0.0043 & -0.0204 \\
\hline
\end{tabular}

Observations:

\begin{tabular}{|l|l|l|l|l|l|}
\hline & 0 yrs & 1 yr & $2-3$ & $4+$ & Total \\
\hline $1 \mathrm{yr}$ & 3,852 & -- & -- & -- & 3,852 \\
\hline $1+1$ & 80 & -- & -- & -- & 80 \\
\hline 2 yrs & 298 & 334 & -- & -- & 632 \\
\hline $3-4$ & 334 & 379 & 494 & -- & 1,207 \\
\hline $5+$ & 74 & 86 & 190 & 147 & 497 \\
\hline Total & 4,638 & 799 & 684 & 147 & 6,268 \\
\hline
\end{tabular}

Panel B: Pitchers

\begin{tabular}{|l|l|l|l|l|l|}
\hline & $0 \mathrm{yrs}$ & $1 \mathrm{yr}$ & $2-3$ & $4+$ & \\
\hline $1 \mathrm{yr}$ & 0.0001 & & & & \\
\hline $1+1$ & 0.0006 & & & & \\
\hline $2 \mathrm{yrs}$ & -0.0082 & 0.0153 & -0.2142 & & \\
\hline $3-4$ & 0.0020 & -0.0037 & 0.0198 & 0.0148 & \\
\hline $5+$ & -0.0274 & -0.0003 & 0.0042 & 0.0093 & \\
\hline
\end{tabular}

Observations:

\begin{tabular}{|l|l|l|l|l|l|}
\hline & $0 \mathrm{yrs}$ & $1 \mathrm{yr}$ & $2-3$ & $4+$ & Total \\
\hline $1 \mathrm{yr}$ & 3,935 & & & & 3,935 \\
\hline $1+1$ & 66 & & & & 66 \\
\hline $2 \mathrm{yrs}$ & 271 & 292 & 1 & & 564 \\
\hline $3-4$ & 214 & 263 & 351 & 3 & 831 \\
\hline $5+$ & 15 & 18 & 36 & 29 & 98 \\
\hline Total & 4,501 & 573 & 388 & 32 & 5,494 \\
\hline
\end{tabular}

Note: Rows represent contract length and columns represent years remaining on contract. Measure reported is the component of differenced OPS (OPS against) that cannot be explained by variation in age group and performance quintile. 
Table 12a: Contracts by contract length and performance quintile, hitters

\begin{tabular}{|l|l|l|l|l|l|l|}
\hline & q1 & q2 & q3 & q4 & q5 & Total \\
\hline $1 \mathrm{yr}$ & 1,649 & 1,476 & 1,346 & 1,125 & 844 & 6,440 \\
\hline $1+1$ & 6 & 22 & 22 & 22 & 26 & 98 \\
\hline $2 \mathrm{yr}$ & 59 & 80 & 95 & 94 & 64 & 392 \\
\hline $3-4$ & 32 & 59 & 79 & 110 & 124 & 404 \\
\hline $5+$ & 9 & 12 & 13 & 29 & 60 & 123 \\
\hline Total & 1,755 & 1,649 & 1,555 & 1,380 & 1,118 & 7,457 \\
\hline
\end{tabular}

Row percentages:

\begin{tabular}{|l|l|l|l|l|l|l|}
\hline & $\mathrm{q} 1$ & $\mathrm{q} 2$ & $\mathrm{q} 3$ & $\mathrm{q} 4$ & $\mathrm{q} 5$ & Total \\
\hline $1 \mathrm{yr}$ & 25.61 & 22.92 & 20.90 & 17.47 & 13.11 & 100.00 \\
\hline $1+1$ & 6.12 & 22.45 & 22.45 & 22.45 & 26.53 & 100.00 \\
\hline $2 \mathrm{yr}$ & 15.05 & 20.41 & 24.23 & 23.98 & 16.33 & 100.00 \\
\hline $3-4$ & 7.92 & 14.60 & 19.55 & 27.23 & 30.69 & 100.00 \\
\hline $5+$ & 7.32 & 9.76 & 10.57 & 23.58 & 48.78 & 100.00 \\
\hline Total & 23.53 & 22.11 & 20.85 & 18.51 & 14.99 & 100.00 \\
\hline
\end{tabular}

Column Percentages:

\begin{tabular}{|l|l|l|l|l|l|l|}
\hline & $\mathrm{q} 1$ & $\mathrm{q} 2$ & $\mathrm{q} 3$ & $\mathrm{q} 4$ & $\mathrm{q} 5$ & Total \\
\hline $1 \mathrm{yr}$ & 93.96 & 89.51 & 86.56 & 81.52 & 75.49 & 86.36 \\
\hline $1+1$ & 0.34 & 1.33 & 1.41 & 1.59 & 2.33 & 1.31 \\
\hline $2 \mathrm{yr}$ & 3.36 & 4.85 & 6.11 & 6.81 & 5.72 & 5.26 \\
\hline $3-4$ & 1.82 & 3.58 & 5.08 & 7.97 & 11.09 & 5.42 \\
\hline $5+$ & 0.51 & 0.73 & 0.84 & 2.10 & 5.37 & 1.65 \\
\hline Total & 100.00 & 100.00 & 100.00 & 100.00 & 100.00 & 100.00 \\
\hline
\end{tabular}

Note: The null hypothesis of independence between contract length and performance quintile is rejected at the $1 \%$ significance level $\left(\chi^{2}=335.8, p=0.000\right)$. 
Table 12b: Contracts by contract length and performance quintile, pitchers

\begin{tabular}{|l|l|l|l|l|l|l|}
\hline & $\mathrm{q} 1$ & $\mathrm{q} 2$ & $\mathrm{q} 3$ & $\mathrm{q} 4$ & $\mathrm{q} 5$ & Total \\
\hline $1 \mathrm{yr}$ & 1,493 & 1,263 & 1,175 & 1,077 & 998 & 6,006 \\
\hline $1+1$ & 7 & 12 & 10 & 25 & 27 & 81 \\
\hline $2 \mathrm{yr}$ & 24 & 58 & 67 & 83 & 95 & 327 \\
\hline $3-4$ & 16 & 64 & 70 & 75 & 82 & 307 \\
\hline $5+$ & 1 & 8 & 7 & 9 & 7 & 32 \\
\hline Total & 1,541 & 1,405 & 1,329 & 1,269 & 1,209 & 6,753 \\
\hline
\end{tabular}

Row percentages:

\begin{tabular}{|l|l|l|l|l|l|l|}
\hline & $\mathrm{q} 1$ & $\mathrm{q} 2$ & $\mathrm{q} 3$ & $\mathrm{q} 4$ & $\mathrm{q} 5$ & Total \\
\hline $1 \mathrm{yr}$ & 24.86 & 21.03 & 19.56 & 17.93 & 16.62 & 100.00 \\
\hline $1+1$ & 8.64 & 14.81 & 12.35 & 30.86 & 33.33 & 100.00 \\
\hline $2 \mathrm{yr}$ & 7.34 & 17.74 & 20.49 & 25.38 & 29.05 & 100.00 \\
\hline $3-4$ & 5.21 & 20.85 & 22.80 & 24.43 & 26.71 & 100.00 \\
\hline $5+$ & 3.13 & 25.00 & 21.88 & 28.13 & 21.88 & 100.00 \\
\hline Total & 22.82 & 20.81 & 19.68 & 18.79 & 17.90 & 100.00 \\
\hline
\end{tabular}

Column percentages:

\begin{tabular}{|l|l|l|l|l|l|l|}
\hline & $\mathrm{q} 1$ & $\mathrm{q} 2$ & $\mathrm{q} 3$ & $\mathrm{q} 4$ & $\mathrm{q} 5$ & Total \\
\hline $1 \mathrm{yr}$ & 96.89 & 89.89 & 88.41 & 84.87 & 82.55 & 88.94 \\
\hline $1+1$ & 0.45 & 0.85 & 0.75 & 1.97 & 2.23 & 1.20 \\
\hline $2 \mathrm{yr}$ & 1.56 & 4.13 & 5.04 & 6.54 & 7.86 & 4.84 \\
\hline $3-4$ & 1.04 & 4.56 & 5.27 & 5.91 & 6.78 & 4.55 \\
\hline $5+$ & 0.06 & 0.57 & 0.53 & 0.71 & 0.58 & 0.47 \\
\hline Total & 100.00 & 100.00 & 100.00 & 100.00 & 100.00 & 100.00 \\
\hline
\end{tabular}

Note: The null hypothesis of independence between contract length and performance quintile is rejected at the $1 \%$ significance level $\left(\chi^{2}=182.3, p=0.000\right)$. 
Table 13: Fraction of players with multi-year deals by performance quintile and CBA regime

Panel A: Batters

\begin{tabular}{|l|l|l|l|l|l|l|}
\hline & $\mathrm{q} 1$ & $\mathrm{q} 2$ & $\mathrm{q} 3$ & $\mathrm{q} 4$ & $\mathrm{q} 5$ & Total \\
\hline $1981-85$ & 0.2738 & 0.3378 & 0.3200 & 0.3261 & 0.4286 & 0.3200 \\
\hline $1986-89$ & 0.0166 & 0.0241 & 0.0918 & 0.0881 & 0.0945 & 0.0518 \\
\hline $1990-94$ & 0.0542 & 0.0674 & 0.0978 & 0.1672 & 0.1903 & 0.1088 \\
\hline $1995-01$ & 0.0579 & 0.0979 & 0.1236 & 0.1820 & 0.2381 & 0.1355 \\
\hline $2002-06$ & 0.0417 & 0.1003 & 0.1185 & 0.1747 & 0.2754 & 0.1325 \\
\hline $2007-$ & 0.0794 & 0.2063 & 0.1471 & 0.2453 & 0.3030 & 0.1821 \\
\hline Total & 0.0570 & 0.0916 & 0.1203 & 0.1688 & 0.2218 & 0.1232 \\
\hline
\end{tabular}

Panel B: Pitchers

\begin{tabular}{|l|l|l|l|l|l|l|}
\hline & $\mathrm{q} 1$ & $\mathrm{q} 2$ & $\mathrm{q} 3$ & $\mathrm{q} 4$ & $\mathrm{q} 5$ & Total \\
\hline $1981-85$ & 0.1042 & 0.3265 & 0.1842 & 0.1778 & 0.1935 & 0.1991 \\
\hline $1986-89$ & 0.0000 & 0.0488 & 0.0326 & 0.0613 & 0.0837 & 0.0493 \\
\hline $1990-94$ & 0.0052 & 0.0485 & 0.0542 & 0.1032 & 0.1206 & 0.0722 \\
\hline $1995-01$ & 0.0235 & 0.0704 & 0.1438 & 0.1623 & 0.1970 & 0.1086 \\
\hline $2002-06$ & 0.0326 & 0.1299 & 0.1651 & 0.1791 & 0.1843 & 0.1189 \\
\hline $2007-$ & 0.0522 & 0.2258 & 0.2432 & 0.2439 & 0.0952 & 0.1448 \\
\hline Total & 0.0266 & 0.0925 & 0.1084 & 0.1316 & 0.1522 & 0.0986 \\
\hline
\end{tabular}


Table 14. Probit regressions of the likelihood of a multi-year contract (2+ years), by experience group, for batters and pitchers.

\begin{tabular}{|c|c|c|c|c|c|c|c|c|}
\hline & \multicolumn{4}{|c|}{ Batters } & \multicolumn{4}{|c|}{ Pitchers } \\
\hline & \multicolumn{2}{|c|}{ All contracts } & \multicolumn{2}{|c|}{$6+$ yrs experience } & \multicolumn{2}{|c|}{ All contracts } & \multicolumn{2}{|c|}{$6+$ yrs experience } \\
\hline & mar eff & std err & mar eff & std err & mar eff & std err & mar eff & std err \\
\hline age 23 -under & $-0.0767^{\mathrm{A}}$ & 0.0066 & -- & -- & $-0.0539^{A}$ & 0.0050 & -- & -- \\
\hline age $24-25$ & $-0.0715^{\mathrm{A}}$ & 0.0069 & 0.0053 & 0.1076 & $-0.0488^{\mathrm{A}}$ & 0.0055 & -0.0831 & 0.0731 \\
\hline age $30-33$ & $0.1001^{\mathrm{A}}$ & 0.0113 & 0.0155 & 0.0184 & $0.0810^{\mathrm{A}}$ & 0.0104 & $0.0392^{\mathrm{B}}$ & 0.0201 \\
\hline age $34-37$ & $0.0716^{\mathrm{A}}$ & 0.0149 & -0.0383 & 0.0201 & $0.0752^{\mathrm{A}}$ & 0.0153 & 0.0064 & 0.0241 \\
\hline age 38 -over & $-0.0585^{A}$ & 0.0117 & $-0.1806^{\mathrm{A}}$ & 0.0155 & -0.0065 & 0.0134 & $-0.1131^{\mathrm{A}}$ & 0.0223 \\
\hline ops Q2 & $0.0440^{\mathrm{A}}$ & 0.0135 & $0.0570^{\mathrm{B}}$ & 0.0272 & $0.1066^{\mathrm{A}}$ & 0.0175 & $0.2053^{\mathrm{A}}$ & 0.0482 \\
\hline ops Q3 & $0.0955^{\mathrm{A}}$ & 0.0157 & $0.1402^{\mathrm{A}}$ & 0.0303 & $0.1234^{\mathrm{A}}$ & 0.0188 & $0.2166^{\mathrm{A}}$ & 0.0459 \\
\hline ops Q4 & $0.1706^{\mathrm{A}}$ & 0.0188 & $0.2231^{\mathrm{A}}$ & 0.0323 & $0.1667^{\mathrm{A}}$ & 0.0215 & $0.2739^{\mathrm{A}}$ & 0.0468 \\
\hline ops Q5 & $0.2728^{\mathrm{A}}$ & 0.0233 & $0.3384^{\mathrm{A}}$ & 0.0366 & $0.1896^{\mathrm{A}}$ & 0.0233 & $0.3146^{\mathrm{A}}$ & 0.0485 \\
\hline LH closer & & & & & $0.2730^{\mathrm{A}}$ & 0.0576 & $0.4854^{\mathrm{A}}$ & 0.0755 \\
\hline LH mid-relief & & & & & $0.0319^{\mathrm{A}}$ & 0.0116 & $0.1007^{\mathrm{A}}$ & 0.0315 \\
\hline LH starter & & & & & $0.1888^{\mathrm{A}}$ & 0.0220 & $0.3456^{\mathrm{A}}$ & 0.0408 \\
\hline RH closer & & & & & $0.0946^{\mathrm{A}}$ & 0.0182 & $0.2141^{\mathrm{A}}$ & 0.0407 \\
\hline RH starter & & & & & $0.1167^{\mathrm{A}}$ & 0.0119 & $0.2213^{A}$ & 0.0270 \\
\hline $2 \mathrm{~B}$ & 0.0144 & 0.0150 & 0.0087 & 0.0316 & & & & \\
\hline $3 \mathrm{~B}$ & -0.0003 & 0.0132 & -0.0447 & 0.0265 & & & & \\
\hline $\mathrm{C}$ & 0.0161 & 0.0137 & 0.0262 & 0.0290 & & & & \\
\hline DH & -0.0228 & 0.0325 & -0.0414 & 0.0639 & & & & \\
\hline OF & 0.0047 & 0.0106 & -0.0020 & 0.0233 & & & & \\
\hline SS & $0.0715^{\mathrm{A}}$ & 0.0200 & $0.0902^{\mathrm{B}}$ & 0.0401 & & & & \\
\hline cba 1981-85 & $0.3428^{\mathrm{A}}$ & 0.0388 & $0.4451^{\mathrm{A}}$ & 0.0478 & $0.1806^{\mathrm{A}}$ & 0.0385 & $0.3567^{\mathrm{A}}$ & 0.0627 \\
\hline cba 1990-94 & $0.0605^{\mathrm{A}}$ & 0.0154 & $0.1386^{\mathrm{A}}$ & 0.0322 & $0.0337^{\mathrm{A}}$ & 0.0130 & $0.0908^{\mathrm{A}}$ & 0.0354 \\
\hline cba 1995-01 & $0.0723^{\mathrm{A}}$ & 0.0139 & $0.1535^{\mathrm{A}}$ & 0.0291 & $0.0867^{\mathrm{A}}$ & 0.0131 & $0.2241^{\mathrm{A}}$ & 0.0332 \\
\hline cba 2002-06 & $0.0693^{\mathrm{A}}$ & 0.0163 & $0.0927^{\mathrm{A}}$ & 0.0311 & $0.1180^{\mathrm{A}}$ & 0.0186 & $0.2196^{\mathrm{A}}$ & 0.0381 \\
\hline cba 2007 & $0.1441^{\mathrm{A}}$ & 0.0332 & $0.2096^{\mathrm{A}}$ & 0.0543 & $0.2091^{\mathrm{A}}$ & 0.0392 & $0.3465^{\mathrm{A}}$ & 0.0639 \\
\hline $\mathrm{N}$ & \multicolumn{2}{|c|}{7457} & \multicolumn{2}{|c|}{3035} & \multicolumn{2}{|c|}{6753} & \multicolumn{2}{|c|}{2408} \\
\hline$\chi^{2}$ & \multicolumn{2}{|c|}{774.7} & \multicolumn{2}{|c|}{291.4} & \multicolumn{2}{|c|}{802.8} & \multicolumn{2}{|c|}{275.5} \\
\hline $\mathrm{P}>\chi^{2}$ & \multicolumn{2}{|c|}{0.000} & \multicolumn{2}{|c|}{0.000} & \multicolumn{2}{|c|}{0.000} & \multicolumn{2}{|c|}{0.000} \\
\hline Pseudo $\mathrm{R}^{2}$ & \multicolumn{2}{|c|}{0.1391} & \multicolumn{2}{|c|}{0.0900} & \multicolumn{2}{|c|}{0.1846} & \multicolumn{2}{|c|}{0.1107} \\
\hline
\end{tabular}

Note: Omitted categories -- Age group: 26 - 29, Performance quintile: q1, Batter

Position: 1B, Pitcher role: RH middle relief, CBA Regime: 1986-1989.

${ }^{A}$ Coefficient significant at $99 \%$ sig.

${ }^{\mathrm{B}}$ Coefficient significant at $95 \%$ sig. 
Table 15. Ordered probit regressions of the likelihood of increasingly long contracts, by experience group, for batters and pitchers.

\begin{tabular}{|c|c|c|c|c|c|c|c|c|}
\hline & \multicolumn{4}{|c|}{ Batters } & \multicolumn{4}{|c|}{ Pitchers } \\
\hline & \multicolumn{2}{|c|}{ All contracts } & \multicolumn{2}{|c|}{$6+$ yrs experience } & \multicolumn{2}{|c|}{ All contracts } & \multicolumn{2}{|c|}{$6+$ yrs experience } \\
\hline & coeff & std err & coeff & std err & coeff & std err & coeff & std err \\
\hline age 23 -under & $-0.7025^{\mathrm{A}}$ & 0.0902 & -- & -- & $-0.7598^{\mathrm{A}}$ & 0.1116 & -- & -- \\
\hline age $24-25$ & $-0.5583^{A}$ & 0.0699 & 0.0553 & 0.3498 & $-0.6103^{A}$ & 0.0847 & -0.2726 & 0.3747 \\
\hline age $30-33$ & $0.4693^{A}$ & 0.0463 & -0.0023 & 0.0605 & $0.5542^{\mathrm{A}}$ & 0.0531 & 0.1286 & 0.0694 \\
\hline age $34-37$ & $0.3289^{\mathrm{A}}$ & 0.0604 & $-0.2135^{\mathrm{A}}$ & 0.0712 & $0.4521^{\mathrm{A}}$ & 0.0714 & -0.0496 & 0.0838 \\
\hline age 38 -over & $-0.4039^{A}$ & 0.1331 & $-0.9525^{A}$ & 0.1385 & 0.0644 & 0.1147 & $-0.4614^{A}$ & 0.1227 \\
\hline ops Q2 & $0.2849^{\mathrm{A}}$ & 0.0672 & $0.2424^{\mathrm{A}}$ & 0.0847 & $0.7060^{\mathrm{A}}$ & 0.0861 & $0.6922^{\mathrm{A}}$ & 0.1285 \\
\hline ops Q3 & $0.5222^{\mathrm{A}}$ & 0.0669 & $0.5006^{\mathrm{A}}$ & 0.0860 & $0.7691^{\mathrm{A}}$ & 0.0869 & $0.6927^{\mathrm{A}}$ & 0.1265 \\
\hline ops Q4 & $0.8252^{\mathrm{A}}$ & 0.0670 & $0.7722^{\mathrm{A}}$ & 0.0867 & $0.9823^{\mathrm{A}}$ & 0.0875 & $0.9282^{\mathrm{A}}$ & 0.1267 \\
\hline ops Q5 & $1.2015^{\mathrm{A}}$ & 0.0703 & $1.2112^{\mathrm{A}}$ & 0.0925 & $1.0614^{\mathrm{A}}$ & 0.0895 & $1.0500^{\mathrm{A}}$ & 0.1291 \\
\hline LH closer & & & & & $1.1082^{\mathrm{A}}$ & 0.1491 & $1.2505^{\mathrm{A}}$ & 0.1814 \\
\hline LH mid-relief & & & & & $0.2133^{\mathrm{A}}$ & 0.0759 & $0.3088^{\mathrm{A}}$ & 0.0936 \\
\hline LH starter & & & & & $1.0019^{\mathrm{A}}$ & 0.0773 & $1.0825^{\mathrm{A}}$ & 0.1007 \\
\hline RH closer & & & & & $0.5630^{\mathrm{A}}$ & 0.0805 & $0.6376^{\mathrm{A}}$ & 0.1032 \\
\hline RH starter & & & & & $0.8295^{\mathrm{A}}$ & 0.0630 & $0.8045^{\mathrm{A}}$ & 0.0793 \\
\hline $2 \mathrm{~B}$ & 0.1268 & 0.0801 & 0.0765 & 0.1021 & & & & \\
\hline $3 \mathrm{~B}$ & 0.0229 & 0.0773 & -0.1175 & 0.0976 & & & & \\
\hline $\mathrm{C}$ & 0.1202 & 0.0736 & 0.1433 & 0.0912 & & & & \\
\hline $\mathrm{DH}$ & -0.1098 & 0.2243 & -0.2057 & 0.2398 & & & & \\
\hline $\mathrm{OF}$ & 0.0544 & 0.0614 & 0.0225 & 0.0767 & & & & \\
\hline SS & $0.4303^{A}$ & 0.0827 & $0.3796^{\mathrm{A}}$ & 0.1112 & & & & \\
\hline cba 1981-85 & $1.3500^{\mathrm{A}}$ & 0.0969 & $1.4603^{\mathrm{A}}$ & 0.1197 & $1.0513^{\mathrm{A}}$ & 0.1217 & $1.2409^{\mathrm{A}}$ & 0.1487 \\
\hline cba 1990-94 & $0.3223^{A}$ & 0.0731 & $0.4307^{\mathrm{A}}$ & 0.0915 & $0.3067^{\mathrm{A}}$ & 0.0883 & $0.3939^{\mathrm{A}}$ & 0.1089 \\
\hline cba 1995-01 & $0.4132^{\mathrm{A}}$ & 0.0685 & $0.5083^{A}$ & 0.0861 & $0.6735^{\mathrm{A}}$ & 0.0812 & $0.7743^{A}$ & 0.0999 \\
\hline cba 2002-06 & $0.4193^{A}$ & 0.0729 & $0.3496^{\mathrm{A}}$ & 0.0916 & $0.7962^{\mathrm{A}}$ & 0.0864 & $0.7987^{\mathrm{A}}$ & 0.1062 \\
\hline cba 2007 & $0.7281^{\mathrm{A}}$ & 0.1038 & $0.7456^{\mathrm{A}}$ & 0.1297 & $1.1200^{\mathrm{A}}$ & 0.1177 & $1.1664^{\mathrm{A}}$ & 0.1496 \\
\hline _cut1 & \multicolumn{2}{|c|}{2.216} & \multicolumn{2}{|c|}{1.621} & \multicolumn{2}{|c|}{3.175} & \multicolumn{2}{|c|}{2.686} \\
\hline cut2 & \multicolumn{2}{|c|}{2.289} & \multicolumn{2}{|c|}{1.721} & \multicolumn{2}{|c|}{3.256} & \multicolumn{2}{|c|}{2.800} \\
\hline _cut3 & \multicolumn{2}{|c|}{2.648} & \multicolumn{2}{|c|}{2.189} & \multicolumn{2}{|c|}{3.682} & \multicolumn{2}{|c|}{3.307} \\
\hline cut4 & \multicolumn{2}{|c|}{3.414} & \multicolumn{2}{|c|}{3.039} & \multicolumn{2}{|c|}{4.814} & \multicolumn{2}{|c|}{4.501} \\
\hline $\mathrm{N}$ & \multicolumn{2}{|c|}{7457} & \multicolumn{2}{|c|}{3035} & \multicolumn{2}{|c|}{6753} & \multicolumn{2}{|c|}{2408} \\
\hline$\chi^{2}$ & \multicolumn{2}{|c|}{916.8} & & & & & & \\
\hline$P>\chi^{2}$ & & & & & & & & \\
\hline Pseudo $\mathrm{R}^{2}$ & 0.1 & & 0.0 & & & & & \\
\hline
\end{tabular}

Note: Omitted categories -- Age group: 26 - 29, Performance quintile: q1, Batter

Position: 1B, Pitcher role: RH middle relief, CBA Regime: 1986-1989.

${ }^{\mathrm{A}}$ Coefficient significant at $99 \%$ sig. 
Table 16. OLS regressions of log-salary, for batters and pitchers

\begin{tabular}{|c|c|c|c|c|c|c|c|c|}
\hline & \multicolumn{4}{|c|}{ Batters } & \multicolumn{4}{|c|}{ Pitchers } \\
\hline & \multicolumn{2}{|c|}{ Model 1} & \multicolumn{2}{|c|}{ Model 2} & \multicolumn{2}{|c|}{ Model 3} & \multicolumn{2}{|c|}{ Model 4} \\
\hline Insalary & Coef. & Std. Err. & Coef. & Std. Err. & Coef. & Std. Err. & Coef. & Std. Err. \\
\hline arbit & $0.770^{\mathrm{A}}$ & 0.027 & $0.707^{\mathrm{A}}$ & 0.023 & $0.692^{\mathrm{A}}$ & 0.025 & $0.677^{\mathrm{A}}$ & 0.022 \\
\hline free & $1.692^{\mathrm{A}}$ & 0.033 & $1.355^{\mathrm{A}}$ & 0.029 & $1.454^{\mathrm{A}}$ & 0.031 & $1.239^{\mathrm{A}}$ & 0.028 \\
\hline ops & $1.197^{\mathrm{A}}$ & 0.066 & $0.806^{\mathrm{A}}$ & 0.057 & $-0.256^{A}$ & 0.067 & $-0.156^{A}$ & 0.060 \\
\hline ops Q2 & $0.154^{\mathrm{A}}$ & 0.025 & $0.145^{\mathrm{A}}$ & 0.022 & $0.214^{\mathrm{A}}$ & 0.026 & $0.150^{\mathrm{A}}$ & 0.023 \\
\hline ops Q3 & $0.329^{\mathrm{A}}$ & 0.026 & $0.261^{\mathrm{A}}$ & 0.023 & $0.416^{\mathrm{A}}$ & 0.027 & $0.337^{\mathrm{A}}$ & 0.024 \\
\hline ops Q4 & $0.591^{\mathrm{A}}$ & 0.028 & $0.426^{\mathrm{A}}$ & 0.024 & $0.478^{\mathrm{A}}$ & 0.028 & $0.361^{\mathrm{A}}$ & 0.025 \\
\hline ops Q5 & $1.012^{\mathrm{A}}$ & 0.030 & $0.698^{\mathrm{A}}$ & 0.027 & $0.604^{\mathrm{A}}$ & 0.029 & $0.471^{\mathrm{A}}$ & 0.027 \\
\hline 1st base & -0.020 & 0.026 & 0.005 & 0.022 & & & & \\
\hline 2nd base & $0.077^{\mathrm{A}}$ & 0.027 & $0.063^{\mathrm{A}}$ & 0.023 & & & & \\
\hline 3rd base & $-0.058^{\mathrm{B}}$ & 0.027 & $-0.045^{\mathrm{B}}$ & 0.023 & & & & \\
\hline Catcher & $-0.137^{A}$ & 0.025 & $-0.127^{A}$ & 0.021 & & & & \\
\hline Des. hitter & 0.171 & 0.094 & $0.264^{\mathrm{A}}$ & 0.080 & & & & \\
\hline Shortstop & $0.265^{A}$ & 0.028 & $0.144^{\mathrm{A}}$ & 0.024 & & & & \\
\hline LH closer & & & & & $0.652^{\mathrm{A}}$ & 0.066 & $0.473^{\mathrm{A}}$ & 0.060 \\
\hline LH mid-rel. & & & & & -0.027 & 0.025 & $-0.050^{\mathrm{B}}$ & 0.023 \\
\hline LH starter & & & & & $0.793^{\mathrm{A}}$ & 0.027 & $0.591^{\mathrm{A}}$ & 0.025 \\
\hline RH closer & & & & & $0.529^{A}$ & 0.030 & $0.423^{\mathrm{A}}$ & 0.027 \\
\hline RH starter & & & & & $0.794^{\mathrm{A}}$ & 0.021 & $0.639^{\mathrm{A}}$ & 0.019 \\
\hline age 23-u & $-0.435^{\mathrm{A}}$ & 0.037 & $-0.377^{\mathrm{A}}$ & 0.032 & $-0.444^{\mathrm{A}}$ & 0.034 & $-0.390^{\mathrm{A}}$ & 0.030 \\
\hline age $24-25$ & $-0.238^{A}$ & 0.028 & $-0.221^{\mathrm{A}}$ & 0.024 & $-0.267^{\mathrm{A}}$ & 0.026 & $-0.230^{\mathrm{A}}$ & 0.024 \\
\hline age $30-33$ & 0.020 & 0.025 & -0.034 & 0.021 & $0.097^{\mathrm{A}}$ & 0.025 & 0.038 & 0.022 \\
\hline age $34-37$ & $-0.129^{A}$ & 0.031 & -0.046 & 0.027 & $0.098^{\mathrm{A}}$ & 0.033 & $0.058^{\mathrm{B}}$ & 0.029 \\
\hline age 38-up & $-0.262^{A}$ & 0.053 & 0.016 & 0.046 & -0.047 & 0.049 & 0.074 & 0.044 \\
\hline newstad & -0.027 & 0.030 & -0.030 & 0.025 & 0.000 & 0.030 & -0.005 & 0.027 \\
\hline newstadsoon & $-0.082^{\mathrm{B}}$ & 0.035 & $-0.076^{\mathrm{B}}$ & 0.030 & 0.000 & 0.035 & -0.014 & 0.032 \\
\hline teamsalhi & $0.128^{\mathrm{A}}$ & 0.020 & $0.064^{\mathrm{A}}$ & 0.017 & $0.239^{\mathrm{A}}$ & 0.021 & $0.177^{\mathrm{A}}$ & 0.019 \\
\hline teamsallo & $-0.155^{\mathrm{A}}$ & 0.021 & $-0.102^{\mathrm{A}}$ & 0.018 & $-0.173^{A}$ & 0.021 & $-0.142^{\mathrm{A}}$ & 0.019 \\
\hline $2 \mathrm{~d}$ yr of $\mathrm{c}$. & & & $-0.338^{\mathrm{A}}$ & 0.097 & & & -0.183 & 0.131 \\
\hline $3 \mathrm{rd} / 4$ th yr. & & & $-0.424^{\mathrm{A}}$ & 0.116 & & & $-0.393^{\mathrm{B}}$ & 0.165 \\
\hline $5+y r$ of $c$. & & & $-0.755^{\mathrm{A}}$ & 0.239 & & & $-1.367^{\mathrm{A}}$ & 0.457 \\
\hline $1+1$ deal & & & $0.162^{\mathrm{B}}$ & 0.068 & & & $0.164^{\mathrm{B}}$ & 0.072 \\
\hline $2 \mathrm{yr}$ deal & & & $0.509^{\mathrm{A}}$ & 0.027 & & & $0.617^{\mathrm{A}}$ & 0.028 \\
\hline $3-4$ yr deal & & & $1.120^{\mathrm{A}}$ & 0.022 & & & $1.004^{\mathrm{A}}$ & 0.025 \\
\hline $5+$ yr deal & & & $1.312^{\mathrm{A}}$ & 0.033 & & & $1.214^{\mathrm{A}}$ & 0.063 \\
\hline $\mathrm{N}$ (observations) & \multicolumn{2}{|c|}{9406} & \multicolumn{2}{|c|}{9406} & \multicolumn{2}{|c|}{7968} & \multicolumn{2}{|c|}{7968} \\
\hline Adj. R-squared & \multirow{2}{*}{\multicolumn{2}{|c|}{$\begin{array}{l}.6735 \\
441.9\end{array}$}} & \multirow{2}{*}{\multicolumn{2}{|c|}{$\begin{array}{l}.7599 \\
584.5\end{array}$}} & \multirow{2}{*}{\multicolumn{2}{|c|}{$\frac{.7023}{4380}$}} & \multicolumn{2}{|c|}{.7608} \\
\hline F-stat & & & & & & & & \\
\hline
\end{tabular}

Note: Omitted categories -- Age group: 26 - 29, Performance quintile: Q1, Batter

Position: OF, Pitcher role: RH middle relief.

Regressions also included set of annual fixed effects.

${ }^{A}$ Coefficient significant at $99 \%$ sig. ${ }^{B}$ Coefficient significant at $95 \%$ sig. 
Table 17. Two-stage least squares regressions of (1) contract length (in years) and (2) $\ln$ (salary), for batters and pitchers.

\begin{tabular}{|c|c|c|c|c|c|c|c|c|}
\hline & \multicolumn{4}{|c|}{ Batters } & \multicolumn{4}{|c|}{ Pitchers } \\
\hline & \multicolumn{2}{|c|}{ Deal length } & \multicolumn{2}{|c|}{$\ln$ (salary) } & \multicolumn{2}{|c|}{ Deal length } & \multicolumn{2}{|c|}{$\ln$ (salary) } \\
\hline & coeff & std err & coeff & std err & coeff & std err & coeff & std err \\
\hline $\ln$ (salary) & $0.862^{\mathrm{A}}$ & 0.013 & & & $0.527^{\mathrm{A}}$ & 0.012 & & \\
\hline deal length & & & $0.811^{\mathrm{A}}$ & 0.163 & & & $1.602^{\mathrm{A}}$ & 0.246 \\
\hline age 23-under & $0.669^{\mathrm{A}}$ & 0.046 & & & $0.330^{\mathrm{A}}$ & 0.035 & & \\
\hline age $24-25$ & $0.462^{\mathrm{A}}$ & 0.037 & & & $0.165^{\mathrm{A}}$ & 0.028 & & \\
\hline age $30-33$ & $-0.074^{\mathrm{B}}$ & 0.030 & & & 0.010 & 0.025 & & \\
\hline age $34-37$ & $-0.309^{A}$ & 0.039 & & & $-0.087^{\mathrm{A}}$ & 0.033 & & \\
\hline age 38 -over & $-0.727^{\mathrm{A}}$ & 0.071 & & & $-0.442^{\mathrm{A}}$ & 0.051 & & \\
\hline OPS / OPSalwd & & & $0.654^{\mathrm{A}}$ & 0.093 & & & $-0.179^{\mathrm{B}}$ & 0.088 \\
\hline ops Q2 & & & $0.152^{\mathrm{A}}$ & 0.026 & & & $0.064^{C}$ & 0.038 \\
\hline ops Q3 & & & $0.249^{\mathrm{A}}$ & 0.027 & & & $0.231^{\mathrm{A}}$ & 0.040 \\
\hline ops Q4 & & & $0.367^{\mathrm{A}}$ & 0.034 & & & $0.213^{\mathrm{A}}$ & 0.046 \\
\hline ops Q5 & & & $0.461^{\mathrm{A}}$ & 0.069 & & & $0.310^{\mathrm{A}}$ & 0.050 \\
\hline LH closer & & & & & $0.122^{\mathrm{C}}$ & 0.072 & $0.350^{\mathrm{A}}$ & 0.091 \\
\hline LH mid-relief & & & & & $0.070^{B}$ & 0.028 & -0.043 & 0.033 \\
\hline LH starter & & & & & $0.151^{\mathrm{A}}$ & 0.031 & $0.281^{\mathrm{A}}$ & 0.065 \\
\hline RH closer & & & & & 0.012 & 0.033 & $0.326^{\mathrm{A}}$ & 0.045 \\
\hline RH starter & & & & & -0.003 & 0.025 & $0.410^{\mathrm{A}}$ & 0.047 \\
\hline 1B & -0.117 & 0.037 & 0.024 & 0.027 & & & & \\
\hline $2 \mathrm{~B}$ & $-0.112^{A}$ & 0.038 & $0.065^{\mathrm{B}}$ & 0.028 & & & & \\
\hline $3 \mathrm{~B}$ & -0.003 & 0.037 & -0.042 & 0.027 & & & & \\
\hline $\mathrm{C}$ & $0.066^{\mathrm{C}}$ & 0.034 & $-0.115^{\mathrm{A}}$ & 0.025 & & & & \\
\hline $\mathrm{DH}$ & $-0.308^{\mathrm{B}}$ & 0.131 & $0.390^{\mathrm{A}}$ & 0.099 & & & & \\
\hline SS & $0.082^{\mathrm{B}}$ & 0.039 & 0.059 & 0.036 & & & & \\
\hline free agent & & & $1.404^{\mathrm{A}}$ & 0.065 & & & $1.212^{\mathrm{A}}$ & 0.069 \\
\hline arbitration & & & $0.857^{\mathrm{A}}$ & 0.024 & & & $0.817^{\mathrm{A}}$ & 0.029 \\
\hline New stadium & & & 0.011 & 0.032 & & & 0.061 & 0.041 \\
\hline New stad. soon & & & $-0.069^{C}$ & 0.036 & & & -0.050 & 0.047 \\
\hline High Payroll & & & -0.022 & 0.032 & & & $0.082^{\mathrm{B}}$ & 0.033 \\
\hline Low Payroll & & & $-0.073^{A}$ & 0.023 & & & $-0.136^{\mathrm{A}}$ & 0.028 \\
\hline intercept & $-9.902^{A}$ & 0.170 & $9.792^{\mathrm{A}}$ & 0.147 & $-5.638^{A}$ & 0.150 & $9.530^{\mathrm{A}}$ & 0.236 \\
\hline $\mathrm{N}$ & & & & & 79 & & & \\
\hline F-statistic & & & & & 33 & & & \\
\hline Pseudo $\mathrm{R}^{2}$ & & & & & 0.3 & & & \\
\hline
\end{tabular}

Note: Omitted categories -- Age group: 26 - 29, Performance quintile: q1, Batter

Position: OF, Pitcher role: RH middle relief. The $\ln ($ salary) model included annual fixed-

effects.

${ }^{\mathrm{A}}$ Coefficient significant at $99 \%$ level.

${ }^{\mathrm{B}}$ Coefficient significant at $95 \%$ level.

${ }^{\mathrm{C}}$ Coefficient significant at $90 \%$ level. 